\title{
Acylated Ghrelin Directly Modulates In Vitro Cytokine Secretion in Lipopolysaccharide-Stimulated Bone Marrow- Derived Macrophages from Male C57BL/6J Mice
}

By

Alexander Wiseman

A thesis submitted to the Faculty of Graduate and Postdoctoral Affairs in partial fulfillment of the requirements for the degree of

\section{Master of Science}

In

Neuroscience

Carleton University

Ottawa, Ontario

(C) 2021

Alexander Wiseman 


\section{Abstract}

Macrophages are the sentinels of the mammalian body and are involved in both inflammatory and reparative functions. Upon activation, macrophages reprogram to bias energy production and the availability of precursor molecules used to kill invading pathogens. Interrupting reprogramming has direct effects on macrophage physiology and host immunity. Macrophages express receptors for the orexigenic peptide ghrelin, and recently this stomach-derived hormone has been shown to influence inflammatory signaling. However, the underlying mechanisms are poorly understood and data available on sex differences is scarce. The objective of the current thesis is to evaluate if ghrelin pre-treatment can directly augment cytokine responses from lipopolysaccharide stimulated bone marrow-derived macrophages from male and female C57BL/6J mice in vitro. We show that pre-treating male macrophages for 4 hours with ghrelin (250 nM) prior to 24 -hour stimulation with lipopolysaccharide $(100 \mathrm{ng} / \mathrm{mL})$ significantly reduces IL$1 \beta, \mathrm{IL}-10$, and TNF- $\alpha$ secretion. This effect was absent in macrophages derived from females. 


\section{Acknowledgements}

I would like to recognize the work of two former graduate students, Alex Edwards and Allison Jaworski - they completed the original study from which the femurs used in the generation of BMDMs for the current thesis were obtained. As well, without the gracious guidance and mentorship of Duale Ahmed, this project would not have been possible. I had the pleasure of working with a couple skilled and intelligent undergraduate students: Maria Papoulias and Sam Tate, who completed their theses alongside me, and contributed many hours and thought-provoking questions that ultimately helped shape this current document. To my supervisors, Dr. Alfonso Abizaid and Dr. Edana Cassol-your guidance, support, and patience with me during this process is unlike any I have ever received. I cannot thank you both enough for your roles in my graduate school experience. To the entire Abizaid Lab, sharing a workplace with you has been a pleasure and a privilege, I have met many intelligent and compassionate people who made tedious lab days much more enjoyable. And lastly, I have family and friends to thank for their generosity and continual support; this work was not just about fulfilling degree requirements, it was also about the continued commitment to personal development. I am incredibly grateful for each one of you that has supported me. 


\section{Table of Contents}

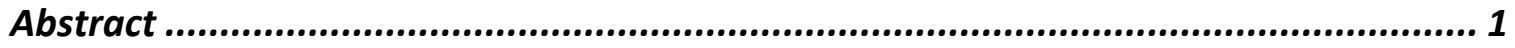

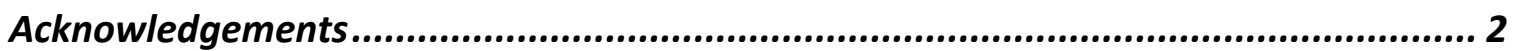

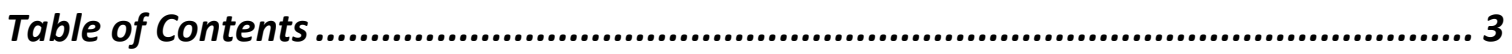

List of Abbreviations ....................................................................................................... 5

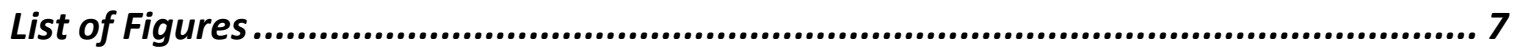

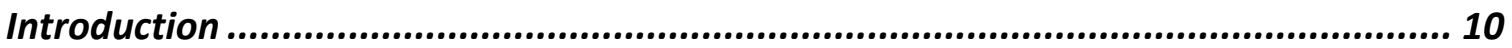

Inflammation, Ghrelin, and the Growth-Hormone Secretagogue Receptor Type 1a ........... 12

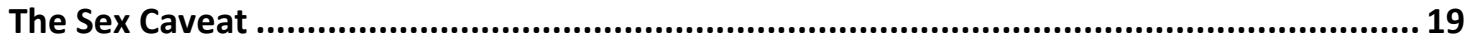

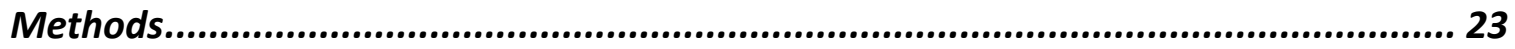

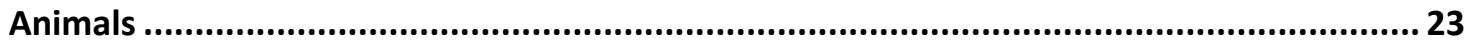

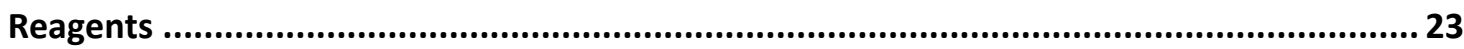

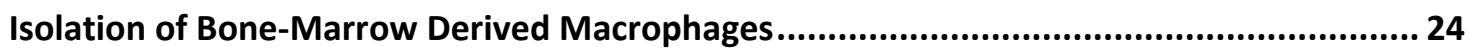

Culture of Bone-Marrow Derived Macrophages................................................................. 25

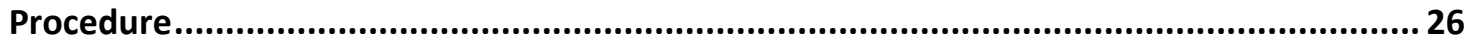

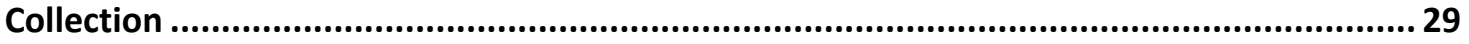

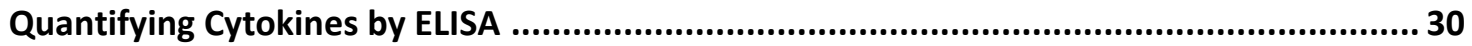

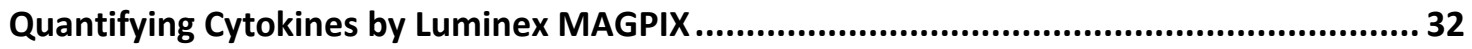

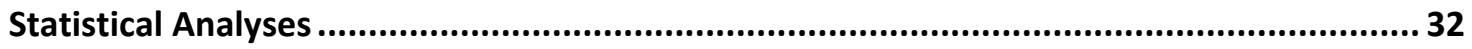

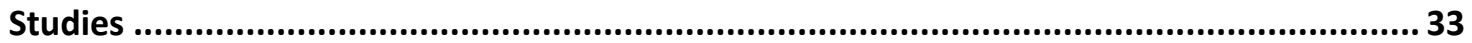

Study 1: Ghrelin degrades in cell-culture media containing foetal bovine calf serum ......... 33

Study 2: Serum-free and serum-containing culture media................................................. 34

Study 3: Ghrelin modulates TLR4- but not TLR3-signaling.................................................. 34

Study 4: Various doses of ghrelin modulate cytokine responses to TLR4 induction............. 35

Study 5: $250 \mathrm{nM}$ ghrelin augments cytokine responses to LPS in male macrophages.......... 36

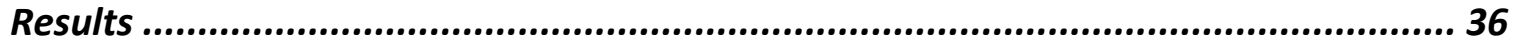

Study 1: Determination of acyl-ghrelin stability in $37^{\circ} \mathrm{C}$ serum ......................................... 36

Study 2: Serum-free and serum-containing culture media................................................. 38

Study 3: Ghrelin modulates TLR4- but not TLR3-signaling............................................. 40

Study 4: Various doses of ghrelin modulate the response to TLR4 induction ...................... 41

Study 5: 250nM ghrelin augments cytokine responses to LPS in male macrophages........... 43

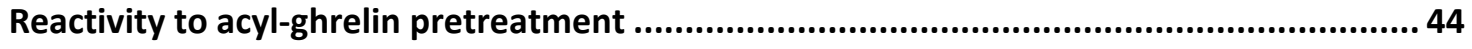




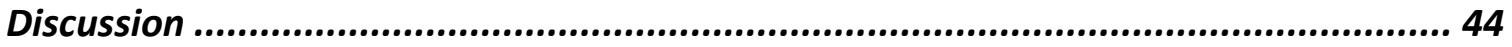

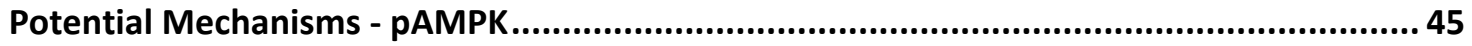

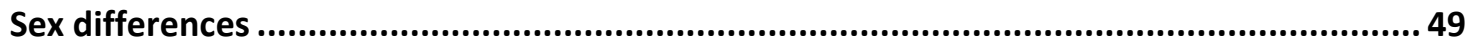

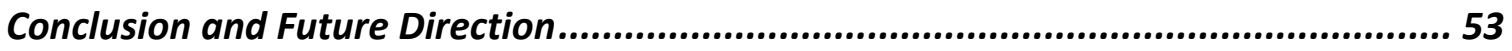

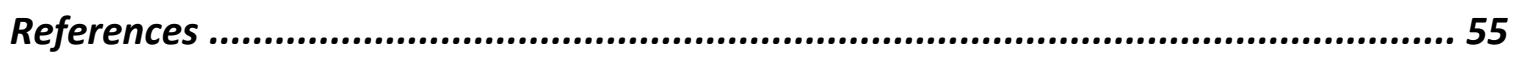




\section{List of Abbreviations}

LPS - Lipopolysaccharide

GHSR - Growth Hormone Secretagogue Receptor

BMDM - Bone Marrow Derived Macrophage

TNF- $\alpha$ - Tumor Necrosis Factor Alpha

IL-1 $\beta$ - Interluekin-1 Beta

IL-6 - Interleukin-6

IL-10 - Interleukin-10

IFN- $\gamma$-Interferon-Gamma

WAT - White Adipose Tissue

$R T-P C R$ - Reverse-Transcription Polymerase Chain Reactions

FFA - Free Fatty Acid

MMe - Macrophage Metabolically Active

ATM - Adipose Tissue Macrophage

LBP - Lipopolysaccharide Binding Protein

MyD88 - Myeloid Differentiation Primary Response Gene 88

TIRAP - TIR Domain-Containing Adaptor Protein

TRAM - TRIF Related Adaptor Molecule

TLR-Toll-Like Receptor

TRIF - TIR Domain-Containing Adaptor Inducing Interferon

IRF3 - Interferon Regulatory Factor-3

ERK - Extracellular Signal-Regulated Kinase 


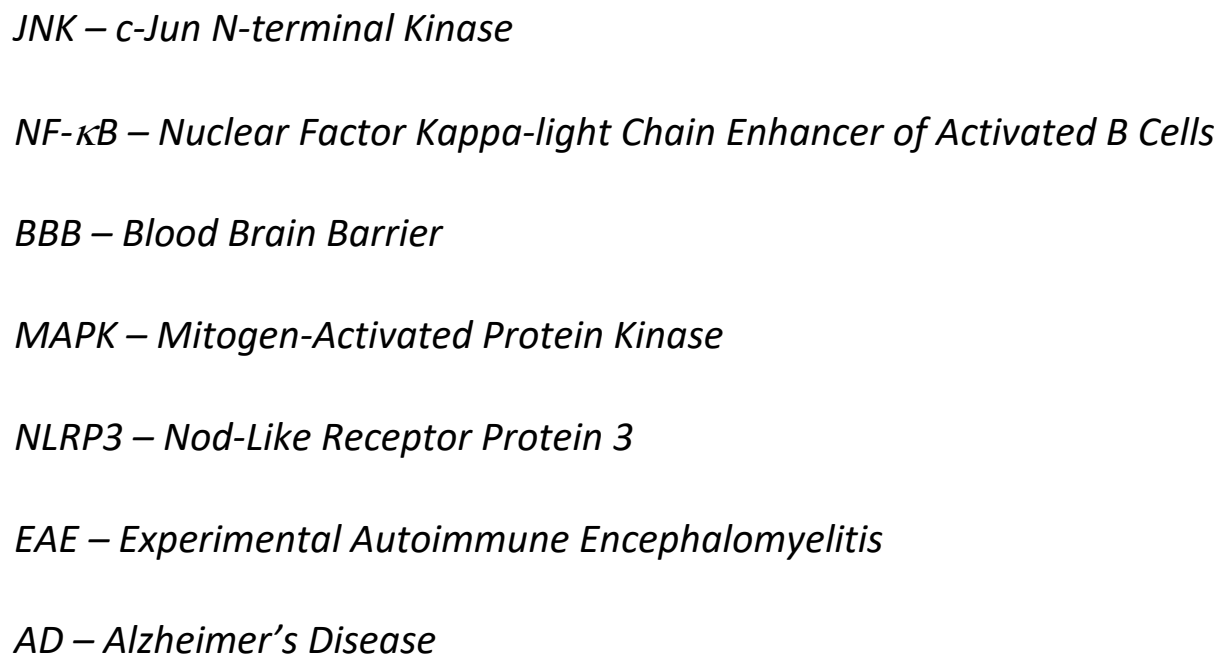




\section{List of Figures}

Figure 1: Femurs are excised from mice, cut on both ends, and flushed with PBS using a syringe. Figure created using Biorender.

Figure 2: Bone-marrow derived cells are treated with cell-culture media containing L929 conditioned media (15\%) to promote maturation of Mø progenitor cells (adherent) for 7 days. Non-adherent cells are transferred to a new vessel - adherent cells are washed with cold PBS, transferred to a falcon tube, counted, and plated. Figure created using Biorender.

Figure 3: Schematic of steps taken for reconstitution of ghrelin $(A)$ and preparation of ghrelin pre-treatment doses (B). Slight miscalculation during treatment preparation step 2 resulted in final ghrelin concentrations $0.007 \%$ higher than expected (precise values are marked with $a *$ in red text) (B). Figure created using Biorender. 28

Figure 4: Sequential plate-mapping of treatments applied, across both treatment periods. Figure created using Biorender.

Figure 5: cells are seeded at a density of 500,000 per well and allowed to adhere to the plastic for 24-hour prior to experimentation. On hour 0 , cells are incubated in the presence or absence of various acyl-ghrelin doses (ranging from 1-250nM) madeup in cell-culture media. At the end of hour 4, media is removed from the wells using a 1,000 uL pipette, and fresh media is added containing LPS at a concentration of $100 \mathrm{ng} / \mathrm{mL}$. Supernatant is collected at the end of hour 28, centrifuged at 12,000 RPM for 15 minutes $\left(4^{\circ} \mathrm{C}\right)$, split into aliquots, and stored at - 
$80^{\circ} \mathrm{C}$ until assaying. IL-10, IL-1 $\beta$, and TNF- $\alpha$ were quantified by sandwich ELISA, R\&D duoset kits. Figure created using Biorender.

Figure 6: $5 \mathrm{ng} / \mathrm{mL}$ of reconstituted acyl-ghrelin (1.5 nM) was aliquoted onto a 24-well cell-culture plate in duplicate at pre-determined time points with and without MAFP (irreversible serine hydrolase inhibitor). 24-well plate was incubated at 37oC, representing experimental conditions of subsequent studies. Absorbance measured in duplicate with iMark and converted to concentration by fitting a 6-pt serial dilution of ghrelin concentration ranging from $0.15-10 \mathrm{ng} / \mathrm{mL}$. Data plotted as percentage of concentration at time $=0$.

Figure 7: BMDMs from male femurs were incubated in serum-containing or serum-free cell-culture media for 12-hours, and then pre-treated with $10 \mathrm{nM}$ acyl-ghrelin for 4hours, followed by 24-hour TLR4 induction at two different doses of LPS: low LPS (100 ng/mL), or high LPS (1 ug/mL). Data represented as mean $+/-\mathrm{SE}$ of $\mathrm{n}=2$ independent experiment. Luminex equipment was used to quantify IL-1 $\beta$ (A, D), IL$10(\mathbf{B}, \mathbf{E})$, and TNF- $\alpha(\mathbf{C}, \mathbf{F})$ 39

Figure 8: BMDMs from male C57BL/6J femurs were pre-treated for 4-hours with $10 \mathrm{nM}$ acyl-ghrelin prior to 24-hour stimulation with either the TLR4 agonist LPS (100 $\mathrm{ng} / \mathrm{mL}$ ) or the TLR3 agonist poly (I:C) $(100 \mathrm{ng} / \mathrm{mL})$. IL-1 $\beta$ (A), IL-10 (B), and TNF- $\alpha$ (C) were quantified by custom 4-plex assays (Invitrogen) on Luminex equipment in duplicate. Average absorbance was converted to concentration by 5P-fitting a serial dilution of known concentration for the analytes. Data are represented at mean +/SE for $n=4$ independent experiment. One-way ANOVA was conducted in Prism at 
the $5 \%$ level of significance with post-hoc multiple paired T-tests and Šidáks correction. ${ }^{*} p<0.05 * * p<0.01 * * * p<0.001 * * * * p<0.0001$

Figure 9: BMDMs from male and female C57BL/6J femurs were pre-treated with various doses of acyl-ghrelin for 4-hours, followed by 24-hour LPS (100 ng/mL). Data represented as mean $+/$ - SE of $n=4$ independent experiments for males, and $n=5$ independent experiments for females. IL-1 $\beta(\mathbf{A}, \mathbf{C})$, and IL-10 (B, D) were quantified by ELISA (R\&D DuoSet) in duplicate. Average absorbance was converted to concentration $(\mathrm{pg} / \mathrm{mL})$ by $4 \mathrm{P}$-fitting a serial dilution of known concentration for the primary antibody. One-way repeated measures ANOVA analysed was conducted in Prism at the $5 \%$ level of significance with post-hot multiple paired T-tests and Šidáks corrections. ${ }^{*} \mathrm{p}<0.05 * * \mathrm{p}<0.01 * * * \mathrm{p}<0.001 * * * * \mathrm{p}<0.0001$ 42

Figure 10: BMDMs from male and female C57BL/6J femurs were pretreated for 4-hours with $250 \mathrm{nM}$ acyl-ghrelin prior to 24-hour stimulation with LPS (100 ng/mL). IL-1ß $(A, D), I L-10(B, E)$, and TNF- $\alpha(C, F)$ were quantified by ELISA (R\&D DuoSet) in duplicate. Average absorbance of duplicates $<10 \%$ CV was converted to concentration $(\mathrm{pg} / \mathrm{mL})$ by $4 \mathrm{P}$ fitting a serial dilution of known concentration for the primary antibody of each analyte. Data are represented as mean $+/-$ SE for $n=7$ independent experiments for males, and $n=6$ independent experiments for females. ANOVA was conducted in Prism at the $5 \%$ level of significance with posthoc multiple paired T-tests and Šidáks correction. ${ }^{*} p<0.05 * * p<0.01 * * * p<0.001$ $* * * * p<0.0001$ 


\section{Introduction}

Chronic inflammation is a critical risk factor for negative mental- and physicalhealth outcomes and early death (Furman et al., 2017; Netea et al., 2017; Slavich, 2015). For instance, cardiovascular disease, cancers, type-2 diabetes, kidney disease, liver disease, neurodegenerative diseases, and autoimmune diseases account for more than $50 \%$ of deaths in humans across the globe, and inflammation is known to play a central role in the progression of these chronic disorders (Roth et al., 2018).

Pathogenic microorganisms that invade the body lead to the initiation of numerous defensive reactions. The activation and mobilization of immune effector cells, accompanying edema and localized inflammation, and a variety of immunogenic mechanisms contribute to the process of immunity. Crucial to the successful defense against pathogens is a complex interactome of upregulating and downregulating immune-specific receptors and ligands, termed the immunoregulatory response. Such response is proportional to the magnitude and type of infection and is regulated by mediating signals (cytokines) and recruiting signals (chemokines) produced by activated immune cells. For instance, when pathogens are detected by macrophages, they increase their activity to support phagocytosis, secrete pro- and anti-inflammatory cytokines into the microenvironment, produce reactive oxygen species, and display fragments of their targets on cell surface complexes, all to rid the body of invaders. As clearance is achieved, pathogenic presence diminishes, and immune activity downregulates. Tissue damage can occur from pathogens and injury, or because of clearance (referred to as collateral 
damage) and part of the immunoregulatory response are reparative processes. Outside of their inflammatory role, macrophages are also crucial for proliferative and remodelling mechanisms involved in healing. In response to tissue damage, macrophages produce angiogenic signals, secrete growth factors, phagocytize dead cells and debris, as well as attract and activate fibroblasts to support collagen production. As such, activated macrophages have a dual role - host defences (phenotypically described as an M1 macrophage), or reparation (phenotypically described as an M2 macrophage). Understanding such dichotomy has been an interest in the immunology community for decades, particularly with respect to maladaptive outcomes that implicate phenotypespecific macrophages - such as M1 macrophages invading synovial fluid cavities of patients with rheumatoid arthritis (Kinne et al., 2007), or M2 macrophages providing angiogenic support to tumours (Qian et al., 2011).

Host metabolism supports immunity and responds in stereotypical patterns with potential contributions to survival. Acute inflammation is accompanied by a number of physiological and behavioral side effects that include fatigue, changes in sleep, anhedonia, social withdrawal, dyslipidemia, insulin resistance, reduced sex-drive, catabolism, fever, and reduced food intake (Straub et al., 2010). Collectively, these behavioural symptoms are a pro-adaptive means of energy conservation and are termed "sickness behaviours", appearing in both mammals and rodents in response to acute infection and injury. Prolonged inflammation, or chronic inflammation can have damaging effects on host-metabolism (Wang \& Ye, 2015). This is likely because homeostatic mechanisms of the innate immune system evolved to cope with acute inflammation 
(Hortová-Kohoutková et al., 2021). During acute infection, engaging the immune system is energetically demanding, estimated at $25 \%$ of the basal metabolic rate (Gong et al., 2020). Under this light, prolonged inflammation is energetically incompatible with life and would thus require significant metabolic reprogramming of the host. Accompanying such reprogramming are changes in the neuroendocrine control of energy homeostasis, which has recently gained traction in the context of regulating host immunity. It has been known for decades that numerous metabolic tissues in the body express cytokine receptors, and in turn promote changes in metabolism that affects local and systemic microenvironments (Shi et al., 2019). In keeping with this, immune cells express many functional receptors for metabolic hormones - likely for the purpose of tissue homeostasis, and as such respond to the nutrient and metabolic status of the body. In fact, numerous metabolic peptide hormones have been identified as immunomodulators, such as glucagon (Kevorkov et al., 1987), glucagon-like peptide 1 (Leme et al., 1975), vasopressin (Russell \& Walley, 2010), leptin (likuni et al., 2008), insulin (Q. Sun et al., 2014), and most recently the gut-derived orexigenic peptide acyl-ghrelin (referred to as ghrelin) (Pereira et al., 2017).

Inflammation, Ghrelin, and the Growth-Hormone Secretagogue Receptor Type 1a

Amongst the receptors for metabolic hormones that are found in immune cells are the receptors for the hormone ghrelin. Ghrelin is a 28-amino-acid polypeptide that is synthesized by the enteroendocrine cells lining the stomach in the gastric mucosa (Kojima et al., 1999). Biological activity of this protein is subject to octanoylation on the $3^{\text {rd }}$ serine 
residue, catalyzed by the enzyme Ghrelin-O-Acyl Transferase (Gutierrez et al., 2008). Ghrelin is secreted in response to negative energy balance (Briggs \& Andrews, 2011). Mostly known for its orexigenic actions in the central nervous system, ghrelin increases appetite (Y. Sun et al., 2004), initiates homeostatic feeding (Wren et al., 2000), and affects reward- and memory-motivated feeding behaviours (Abizaid et al., 2006). Named for its firstly identified role in the pituitary growth hormone axis, the growth-hormone secretagogue receptor type 1a (referred to as GHSR) is the only known functional receptor of ghrelin (Kojima et al., 1999). The GHSR is a G-protein coupled receptor and is widely distributed in mammals and rodents, expression of GHSR has been identified in the brain (hypothalamus, pituitary, ventral tegmental area), lymphoid tissue, bone marrow, testis, pancreas, liver, lungs, gastrointestinal tract, skeletal muscle, skin, appendix, adrenal glands, peripheral blood monocytes and endothelial cells, natural-killer cells, B cells, T cells, dendritic cells, and macrophages (Delporte, 2013; Hattori et al., 2001).

The role of ghrelin on inflammatory processes is complex. In some chronic inflammatory conditions, ghrelin levels seem to be decreased. For example, obesogenic conditions in humans produces chronic-low grade inflammation, reaching systemic levels evident by increased plasma concentrations of TNF- $\alpha$, IL-6, and C-reactive protein which are concomitant with decreased plasma ghrelin levels (Alvarez-Castro et al., 2013). Patients suffering from rheumatoid arthritis have elevated plasma TNF- $\alpha$ and IL-1 $\beta$, as well as decreased ghrelin concentrations (Otero et al., 2004). In contrast, other reports show that other inflammatory conditions are associated with increased expression of ghrelin. For instance, sepsis in humans is associated with increased plasma ghrelin 
(Maruna et al., 2005). LPS administration in healthy humans produces a biphasic ghrelin response dependent on time, whereby a rapid increase of circulating ghrelin is noted 2 hours post injection, and a subsequent decrease by 7 hours (Vila et al., 2007). Severity of cachexia is positively correlated with plasma ghrelin in cystic fibrosis and cancers (Kodama et al., 2008) (Shimizu et al., 2003). Together these data suggest that ghrelin is not a simple acute phase immune-reactant but given the discovery of GHSR mRNA in primary immune tissues such as the thymus and spleen have prompted an effort to investigate the direct effects of ghrelin in the generation of immune responses including pro and antiinflammatory mechanisms.

Reverse-Transcription Polymerase Chain Reactions (RT-PCR) revealed that GHSR is expressed in human B- and T-cells, peripheral blood monocytes, and on tissue macrophages from humans and rodents further supporting the idea that endogenous ghrelin directly affects immune processes. (Dixit et al., 2004; Hattori, 2009). In 2006, Gonzalez et al. utilized a mouse model of colitis to investigate the potential therapeutic effects of ghrelin. By rectal administration of trinitrobenzene sulfonic acid (TBSA), or oral consumption of dextran sulfate sodium (DSS), colitis was modelled in chronic and acute condition, respectively, with and without intraperitoneal injections of ghrelin. This study demonstrated that ghrelin protected against colitis development, rescued body-weight decrease, and suppressed TNF- $\alpha$, MIP-2, IL-1 $\beta$, IL-12, IL-6, and IFN- $\gamma$ concentrations in the colon (Gonzalez-Rey et al., 2006). In a rat model of pancreatitis, exogenous ghrelin administration dose-dependently decreased plasma concentrations of IL-1 $\beta$ (Dembiński et al., 2005). In LPS treated Wistar rats, ghrelin suppressed IL-6, IL-1 $\beta$, TNF- $\alpha$, and IL-10 
(Ziko et al., 2018). Ghrelin also decreased mortality in endotoxic shock model in rats (Chang et al., 2003). In Sprague-Dawley rats, $10 \mathrm{mg} / \mathrm{kg}$ endotoxin challenge produced substantial levels of TNF- $\alpha$ and IL-8. In rats that received concomitant injection of 10 $\mathrm{nmol} / \mathrm{kg}$ ghrelin, plasma concentrations of proinflammatory cytokines returned to levels to that of saline injected rats (W. G. Li et al., 2004).

In vitro experimentation with macrophages has also contributed to our knowledge of the anti-inflammatory properties of ghrelin. Macrophages harvested from the peritoneal cavity of arthritic Wistar rats and treated with LPS showed robust IL-6 secretion in the supernatants, concomitant ghrelin or GHRP-2 (GHSR agonist) treatment suppressed such response (Granado et al., 2005). Alveolar macrophages treated with LPS become apoptotic but additional treatment with ghrelin suppresses apoptosis (B. Li et al., 2015). Adipose tissue macrophages (ATMs) have been implicated in obesogenic inflammation. Excess free fatty acids (FFAs) in the local adipose tissue and blood stream are a known consequence of obesity and are directly related to the inflammatory environment. In fact, FFAs activate resident ATMs and promote a 'metabolically activated' phenotype (MMe) with known pro- and anti-inflammatory signalling pathways that contribute to the systemic inflammation observed in obese humans and rodents (Kratz et al., 2014). MMe can be experimentally induced in various macrophage lines with concomitant glucose, insulin, and palmitate treatments - such phenotype is different from the M1/M2 classical paradigm, but similarly induces numerous proinflammatory cytokines and metabolic changes. Under simulated in vitro modelling of MMes, ghrelin reduced TNF- $\alpha$ secretion and increased IL-12 concentrations from BMDMs and peritoneal macrophages, but not 
ATMs (Corrêa da Silva et al., 2019). In another study using murine macrophages like RAW 264.7 cells, Waseem and colleagues showed that 4-hour pre-treatment of ghrelin (ranging from 1-100nM) prior to 24 -hour LPS (1 ug/mL) stimulation resulted in a dose-dependent suppression of IL-1 $\beta$ and TNF- $\alpha$, and increased anti-inflammatory IL-10 concentrations in the supernatants. Using western blot analysis they also showed that ghrelin specifically inhibits the translocation of $\mathrm{p} 65$ subunits of NF- $\mathrm{kB}$, suggesting that ghrelin suppresses NFKB activation (Waseem et al., 2008). Activated endothelial cells of the cardiovascular system have recently been described as respondents and sources of proinflammatory cytokines and chemokines during systemic inflammatory conditions, such as rheumatoid arthritis and obesity. In vitro experimentation revealed that ghrelin inhibited NF- $\mathrm{\kappa B}$ during basal and TNF- $\alpha$-stimulated conditions in endothelial cells (W. G. Li et al., 2004). Lastly, and most recently in vitro administration of 500nM ghrelin was unable to alter cytokine responses to 100ng/mL LPS in BMDMs (Corrêa da Silva et al., 2019). However, here the authors co-administered ghrelin and LPS simultaneously for 18 hours. Taken together, it is clear that the gut-derived hormone ghrelin modulates inflammatory responses. Similarly, ghrelin secretion is affected in vivo by numerous inflammatory conditions in both humans and rodents. As well, it appears that inflammation is a factor affecting plasma ghrelin concentrations, and that ghrelin affects responses in a variety of of immune cells including peripheral blood monocytes, activated endothelial cells, T- and B-cells, ATMs, alveolar macrophages, peritoneal macrophages, RAW 264.7 macrophages, and BMDMs. 
Ghrelin is an attractive candidate for immunotherapy, especially in chronic inflammatory conditions that are comorbid with wasting-syndromes (catabolizing tissues for energy production) such as cancer cachexia. As well, chronic inflammation can have profound consequences on the central nervous system, such as in multiple sclerosis (Howell et al., 2011; Mahad et al., 2015) and degenerative diseases like Parkinsons' (Adams et al., 2019) and Alzheimer's disease (Walker et al., 2019). Treatments for central nervous system inflammation have limited efficacy and side-effects (Radtke et al., 2017). The inflammasome, nod-like receptor protein 3 (NLRP3) has been shown to be central to the aggressive progression of inflammation in the brain (Lin \& Mei, 2021; Milner et al., 2021; Xiao et al., 2020), interventions that target NLRP3 in microglia are highly sought. Indeed, a recent study found that ghrelin attenuates neuroinflammation in experimental autoimmune encephalomyelitis (EAE), a rat model approximating multiple sclerosis (F. Liu et al., 2019). The authors showed that ghrelin inhibits NF- $\kappa B$ activation, and suppressed TNF- $\alpha$, IL-6, IL-18, and IL-1 $\beta$, the latter two of which are involved in NLRP3 inflammasome signalling (Kelley et al., 2019). Interestingly, during chronic neuroinflammatory conditions, it has been shown that BMDMs can infiltrate the brain parenchyma where they contribute to disease progression through proinflammatory processes. In $E A E$, BMDMs have been shown to be essential for demyelination events (Savarin et al., 2018). BMDMs exacerbate stroke injury (Srivastava et al., 2019), migrate to the lungs during prolonged exposure to air pollutants (Gangwar et al., 2020), infiltrate adipose tissue of obese subjects (Cinti et al., 2005; Weisberg et al., 2003), and are implicated in tumors and various cancers (Takaku et al., 2012). It has also been shown that bone-marrow derived 
cells can mature into microglia within the CNS after gaining access through the BBB during neuroinflammation, where they take-on amyloid- $\beta$ removal in Alzheimer's disease (AD) (C. Li et al., 2020). Other research has shown that negative regulation of MyD88 signalling in BMDMs is necessary for the therapeutic effect in AD pathogenesis. In BMDMs, NLRP3 is activated by direct phosphorylation through MyD88-mediated JNK signaling, specifically JNK-1 (Song et al., 2017), and ghrelin has been shown to negatively regulate JNK signalling in LPS-stimulated alveolar macrophages (B. Li et al., 2015). Given the vast contributions of BMDMs in neuroinflammatory disease, and because ghrelin has been shown to cross the blood-brain barrier (BBB) (Rhea et al., 2018), there is potential for this gut-derived hormone to influence neuroinflammatory processes. Indeed, a recent investigation has shown that ghrelin knock-out mice suffered from faster disease progression in a model of AD, and ghrelin treatment improved cognitive deficits (Santos et al., 2017). Similarly, non-steroidal anti-inflammatory drugs (NSAIDS) received enthusiastic investigations for their potential anti-inflammatory effects in $A D$, however long-term follow-up found no association between naproxen use and $A D$ plaque clearance, although there was a weak association for detrimental effects (Loscalzo, 2008). From 2000-2013, 939 human subjects underwent various ghrelin infusions, adverse events including gastric rumbles with mild discomfort were reported in $2.3 \%$ of study participants, fatigue and vertigo were reported in $2.6 \%$ of volunteers (Garin et al., 2013) - however, the latter two symptoms are common side-effects of many rapid-delivery drugs. In contrast, NSAIDs are reportedly responsible for $30 \%$ of hospital admissions regarding adverse drug effects, mainly due to uncontrolled bleeding, heart attack, and 
stroke (Pirmohamed et al., 2004). As such, given the immaculate safety of ghrelin, and its reportedly potent anti-inflammatory properties, more work is needed to understand the therapeutic effects on BMDMs.

\section{The Sex Caveat}

Sex is a biological variable that affects inflammatory processes of innate immunity, and disease outcome (Washburn et al., 1965). Some aspects of sex-mediated differences have been shown to be germline encoded (Hill-Burns \& Clark, 2009; Libert et al., 2010), while others are associated with androgen- and estrogen-response elements (Mondal \& Rai, 1999). Disparity has been established in acute and chronic inflammatory conditions; males generally have a dampened innate response that leave them more susceptible to acute infection, in contrast, the robust immune response in females is associated with an increased risk of chronic inflammatory disease (Casimir, Mulier, Hanssens, Zylberberg, et al., 2010). Epidemiological analysis of inflammation-mediated disease outcome has elucidated numerous sex differences $-80 \%$ of autoimmune diseases occur in females (Invernizzi et al., 2009), men experience higher viral load in their blood as a consequence of HIV infection (Mosha, 2020), cancer development is $1.5 \mathrm{x}$ more likely in men (Rubin et al., 2020), and females produce a two-fold antibody response to vaccinations in relation to their sexual counterparts (Klein et al., 2010). Several sex-determinant links have been posited and evidenced in experimental findings - most notably are steroid hormones and X-linked genes involved in immune responses. 
A meta-analysis of 244 studies revealed that females demonstrate a reduced microbial infection rate over their lifespan (Ibrahim et al., 2017), potentially owing to the fact that females carry a higher number of circulating monocytes (Y. Chen et al., 2016), and tissue-infiltrated activated macrophages (Melgert et al., 2010). Moreover, macrophages derived from females express IRAK1 more than macrophages derived from males - IRAK1 is an intermediary signal linking TLR4 and IL-1R transduction and to NF-KB activation (O'Driscoll et al., 2017). Whole-blood samples taken from 72 men and 82 women and exposed to low-dose LPS $(100 \mathrm{pg} / \mathrm{mL})$ resulted in significantly more TNF- $\alpha$, IL$1 \beta, \mathrm{IL}-6$, and IL-8 among the female volunteers, after normalizing results to individual's monocyte counts (Aulock et al., 2006). Treatment with LPS at a dose of $0.4 \mathrm{ng} / \mathrm{kg}$ resulted in significantly higher plasma TNF- $\alpha$ and IL-6 in female volunteers (Wegner et al., 2017). High-dose LPS (1-10ug/mL) erased this sex difference. (Wegner et al., 2017). In contrast, a meta-analysis of 15 studies including a total of 4,020 human subjects found that wholeblood samples from men produced a greater TNF- $\alpha, \mathrm{IL}-1 \beta, \mathrm{IL}-6$, and IFN- $\gamma$ response to high-dose LPS - however, after normalizing to individual monocyte count this difference disappeared (Beenakker et al., 2020). Together this suggests that sex is a determinant during mild to moderate infection, but perhaps not in severe inflammatory responses.

Animal models of inflammation have provided insight into estrogens effect on LPS induced inflammation, whereby 17B-estradiol administration increases TLR4 and CD14 cell-surface expression (Rettew et al., 2009). In contrast, testosterone has been shown to decrease TLR4 and CD14 expression on macrophages (Rettew et al., 2008). As well, peritoneal macrophages isolated from ovariectomized female mice have a reduced LPS- 
binding capacity, leading to sub-maximal proinflammatory cytokine secretion in comparison to non-ovariectomized controls (Scotland et al., 2011). In a mouse model of inflammation, Cai and colleagues showed that female mice produced comparably more IL-1 $\beta$, IL-10, and IFN- $\gamma$ 10-hours after low-dose $(1.5 \mathrm{mg} / \mathrm{kg}$ ) LPS injection than males (Cai et al., 2016). In contrast, high-dose LPS $(5 \mathrm{mg} / \mathrm{kg}$ ) resulted in males producing more proinflammatory IL-1 $\beta$ and IL-6 (Marriott et al., 2006).

Taken together, innate immune responses to LPS from rodents and humans are sexually dimorphic. As well, dose effects the dichotomous response such that low-dose endotoxin challenge results in greater proinflammatory secretion from females, whereas males (specifically, mice) respond more to a high-dose. Suggesting that an interaction exists between sex and dose of challenge. Given the sexual dimorphism observable in the human population and rodent models, and the known effects of sex-steroid hormones on macrophage function, very few immunological studies examine the role of sex in the inflammatory response in vitro. The reactivity to ghrelin is seemingly affected by sex differences - generally, the current consensus is that males have a higher affinity and post-binding signalling for ghrelin and the GHSR (Farman et al., 2016; Yamada, 2021), and females secrete more variable levels of ghrelin (Barkan et al., 2003), although many studies have found contradictory results (Currie et al., 2005; Gayle et al., 2006; Makovey et al., 2007; Serra-Prat et al., 2015; Yamada et al., 2020). Despite these known differences, no published in vitro investigation has included sex as a factor with regards to ghrelin's anti-inflammatory effect. In addition, dendritic cells (DC) that develop in adult female mice harbor relaxed chromatin structures at genes that encode type 1 interferons that 
persist in vitro, whereas DCs from males do not (Jansen et al., 2014). As such, it is plausible that other immune cells, such as BMDMs exposed to sex hormones in vivo have lasting epigenetic changes that directly influence inflammatory processes in vitro.

Macrophages are implicated in many inflammatory diseases, and recent work shows that ghrelin potentially modulates proinflammatory processes in these macrophages. Waseem et al. identified anti-inflammatory properties of a 4-hour pretreatment of ghrelin (1-100nM) followed by 24 -hour of LPS induction (1 $\mathrm{ug} / \mathrm{mL})$ on RAW 264.7 murine macrophages (sex not disclosed in publication, although these cells are generally generated in male BALB/c mice), whereas Corrêa da Silva et al. (2019) activated BMDMs from male C57BL/6J mice with $100 \mathrm{ng} / \mathrm{mL}$ LPS with and without concomitant 500 $\mathrm{nM}$ ghrelin. The dose-response of ghrelin, and relationship with sex remains unclear and warrants investigation. Work is needed to examine the dose-response of ghrelin and sexdifferences on cytokine responses in vitro using BMDMs from male and female C57BL/6J mice.

The objective of the current thesis is to further explore the effect of 4-hour ghrelin pre-treatment on inflammatory signaling responses in BMDMs. To accomplish this, the direct aims are as follows:

1. Determine stability of acyl-ghrelin in cell-culture media

2. To investigate differential augmentation by ghrelin pre-treatment in TLR3and TLR4-stimulated models of inflammation.

3. Examine differences between male and female responses to LPS, with and without ghrelin pre-treatment. 


\section{Methods}

Animals

For all experiments, cells were obtained from femurs excised from C57BL/6J mice (Charles River Farms, St Constant Quebec) on approved protocols at Carleton University. Animals were sacrificed following the guidelines of the Canadian Council on Animal Care (CCAC) and approved protocols reviewed by the Carleton University Animal Care Committee (CUACC). All biohazardous materials were handled and stored by trained personnel, and in accordance with the Canadian Biosafety Standards. Disposal of biohazardous waste was carried out in compliance with Guideline C-4, Environment Canada. All reagents, kits, and peptides were used following the manufacturers protocol; summaries of the outlined steps taken are provided where applicable. All biological tissues were protected from contamination by adhering to the aseptic technique in a Thermofisher 1300 Series A2 biological safety cabinet.

Reagents

Media - Gibco Dulbecco's modified eagle medium, $10 \%$ foetal calf serum, $1 \%$ penicillin-streptomycin, 15\% L929 conditioned media. Acylated Ghrelin was procured from Tocris Pharma, and reconstituted in $1 \mathrm{~mL}$ sterile PBS (Gibco), Batch No: 28A. Ultrapure lipopolysaccharide (LPS; E. coli, K12) and Poly(I:C) were purchased from Invivogen and reconstituted in endotoxin-free water following manufacturers protocols. 
Isolation of Bone-Marrow Derived Macrophages

Mice were sacrificed via $\mathrm{CO}^{2}$ asphyxiation. The abdomen and hind legs were sterilized with $70 \%$ ethanol, and a midline incision was made and clipped to expose the hind-legs. Muscle was detached with scissors, and the femurs were briefly sterilized in $70 \%$ ethanol before being transferred to a new dish containing sterile PBS. Ends of the femur were cut-off using scissors, and marrow was flushed-out into a falcon tube using a 26-gague needle containing sterile PBS at the knee-end of the bone. Marrow was dispersed by passing it through a fresh syringe twice, with a 19-gague needle. Cells were centrifuged at 1500 RPM for 5 minutes $\left(4^{\circ} \mathrm{C}\right)$ - pellets were resuspended in $3 \mathrm{~mL}$ of foetal calf serum (FCS) and frozen at $-80^{\circ} \mathrm{C}$ until future use.

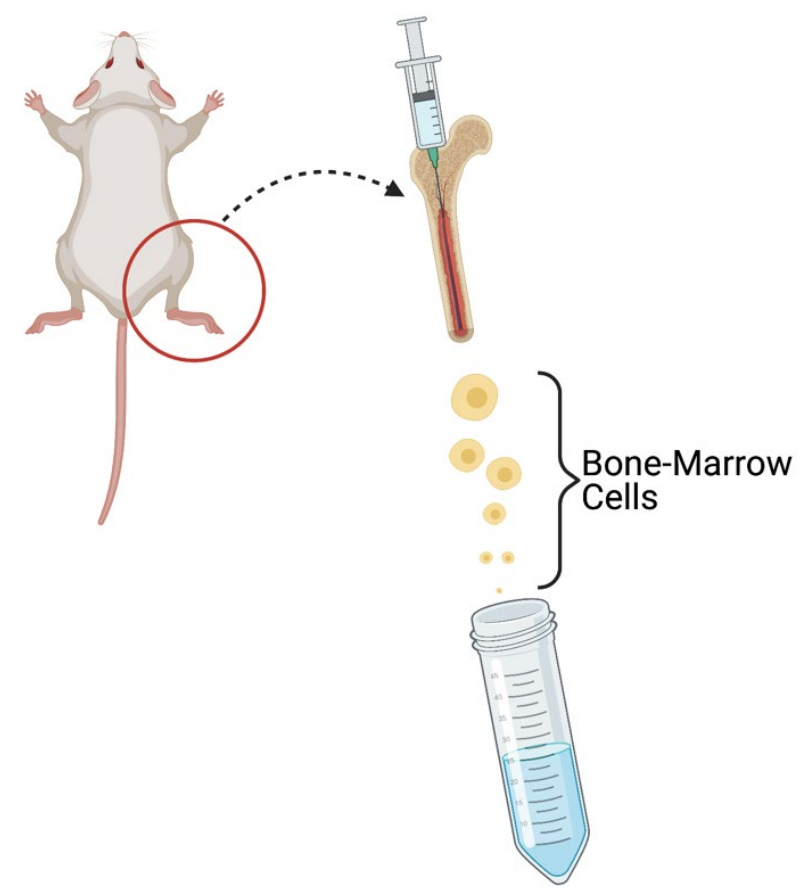

Figure 1: Femurs are excised from mice, cut on both ends, and flushed with PBS using a syringe. Figure created using Biorender. 


\section{Culture of Bone-Marrow Derived Macrophages}

Day 1:

Cells were thawed in a $37^{\circ} \mathrm{C}$ water bath, with gentle mixing, and transferred to a biosafety cabinet. $5 \mathrm{~mL}$ of media were added to a $15 \mathrm{~mL}$ falcon tube and using a $5 \mathrm{~mL}$ serological pipette cells were transferred drop-by-drop. The tube was centrifuged at 1000 RPM for 5 minutes, and media was aspirated prior to the addition of $10 \mathrm{~mL}$ of fresh media. Resuspended cells were then transferred to a sterile petri dish, gentle swirling was applied to distribute the cells. The petri dish was then incubated at $37^{\circ} \mathrm{C}$ and $5 \% \mathrm{CO}_{2}$ for a week in a HERAcell VIOS 160i $\mathrm{CO}_{2}$ incubator (Thermoscientific).

Day 3:

On the third day of the incubation, cells were fed with the addition of $10 \mathrm{~mL}$ of media ( $20 \mathrm{~mL}$ of total media).

Day 7:

By now, adherent cells were attached to the bottom of the petri dish, and nonadherent cells were suspended in the media. All $20 \mathrm{~mL}$ of media were then transferred to a new petri dish and $10 \mathrm{~mL}$ of fresh media were added to the existing dish containing the adherent cells for an overnight incubation.

Day 8:

Petri dishes were allowed to come to room temperature inside a biosafety cabinet. Media was removed and $5 \mathrm{~mL}$ of cold PBS were carefully added around the outside of the dish. An additional $5 \mathrm{~mL}$ of PBS were added to the dish and pipetted up and 
down several times. All $10 \mathrm{~mL}$ were transferred to a $15 \mathrm{~mL}$ tube on ice. Cells were then counted using a hemocytometer and plated evenly onto a 12-well sterile polystyrene plate at a seeding density of $5 \times 10^{5}$ cells per well.

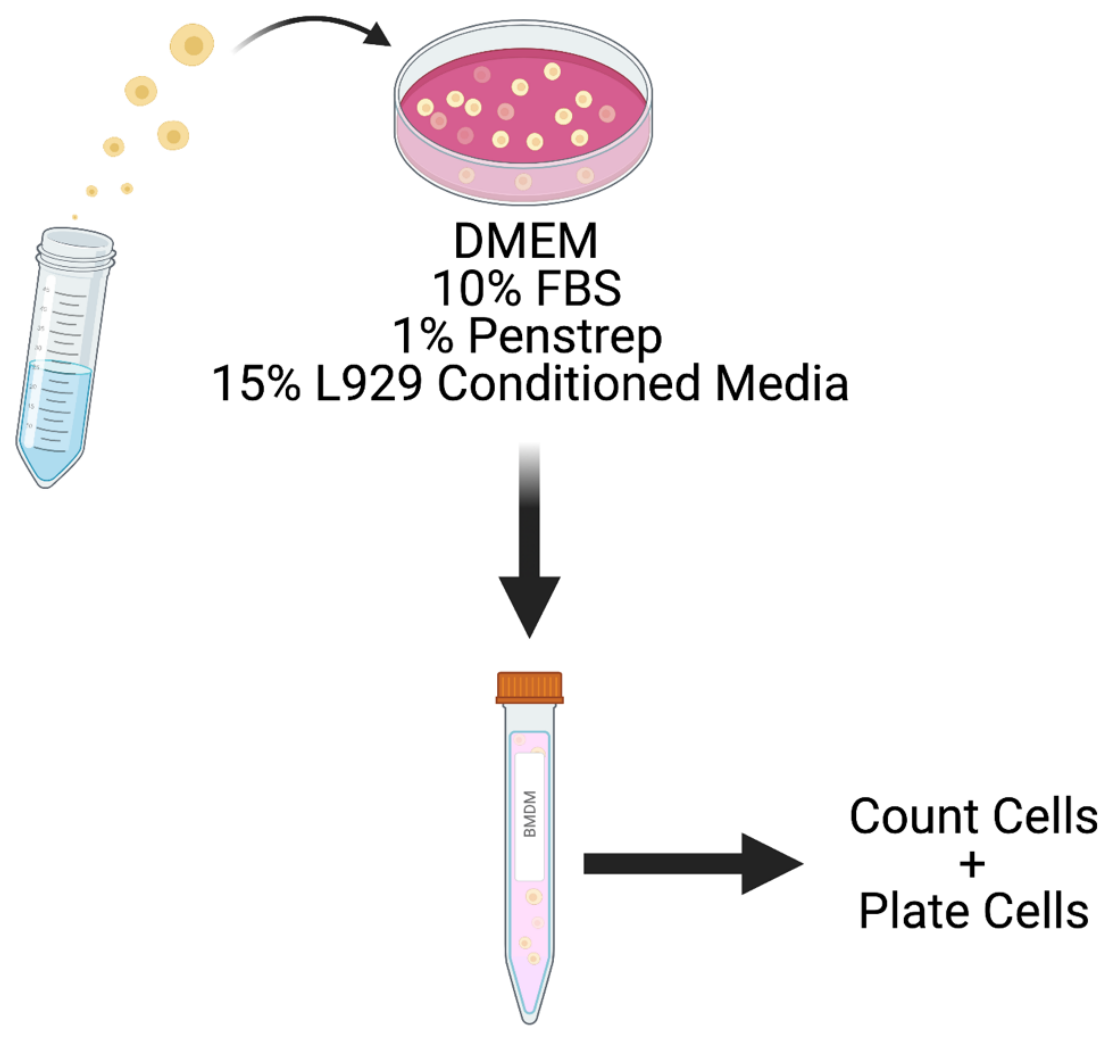

Figure 2: Bone-marrow derived cells are treated with cell-culture media containing L929 conditioned media (15\%) to promote maturation of $M \varnothing$ progenitor cells (adherent) for 7 days. Non-adherent cells are transferred to a new vesseladherent cells are washed with cold PBS, transferred to a falcon tube, counted, and plated. Figure created using Biorender.

Procedure

Experimentation occurred over a 28-hour period, broken into two distinct blocks of time: 1) 4-hour pre-treatment 2) 24-hour treatment. 


\section{Block 1: Ghrelin pre-treatment (4-hours)}

A 20uL aliquot of ghrelin (300uM) was removed from the $-20^{\circ} \mathrm{C}$ freezer and allowed to thaw on ice for 20-30 minutes. In the biosafety cabinet, 980uL of fresh media was added to the ghrelin aliquot, and vortexed on low (6000nM). 187uL was then transferred to a new tube containing 833uL of media - again, vortexed on low (1000nM). Four falcon tubes were placed in the cabinet, and labelled ' $1 \mathrm{nM}^{\prime}$ ', '10nM', '100nM', and '250nM'. To each falcon, fresh media was added in aliquots of $1748.25 \mathrm{uL}, 1732.5 \mathrm{uL}$, $1575 \mathrm{ul}$, and $1312 \mathrm{uL}$, respectively. From the $1000 \mathrm{nM}$ working stock, $1.75 \mathrm{uL}, 17.5 \mathrm{uL}, 175 \mathrm{uL}$, and $438 \mathrm{uL}$ were added to the respective falcon tubes. Each falcon was vortexed on low and placed in a $37^{\circ} \mathrm{C}$ water bath for 5-10 minutes. A 12 -well plate containing adherent macrophages was placed in the cabinet, media was removed, and fresh media with and without various doses of ghrelin were added in 750 uL aliquots to each well. Each condition was applied to two wells. Plate was incubated at $37^{\circ} \mathrm{C}, 5 \% \mathrm{CO}_{2}$ for 4 hours. 
A.

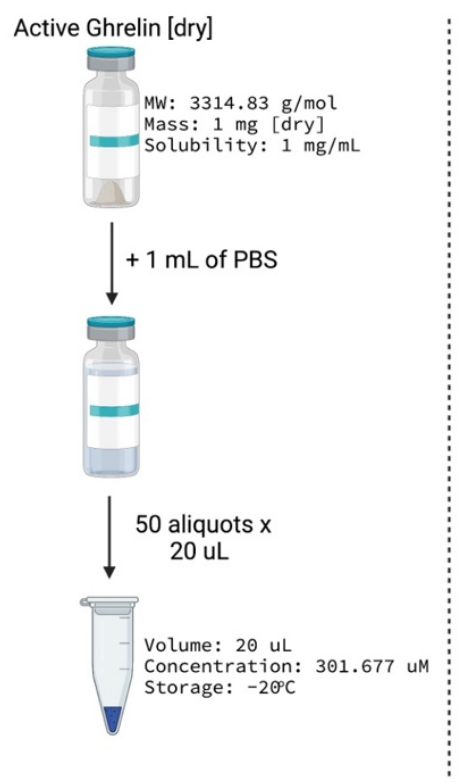

Treatment Preparations

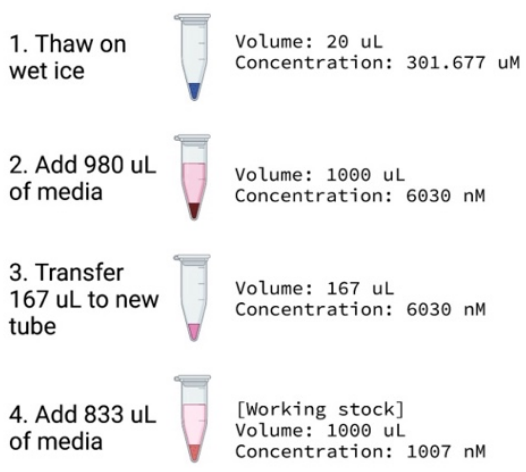

B.

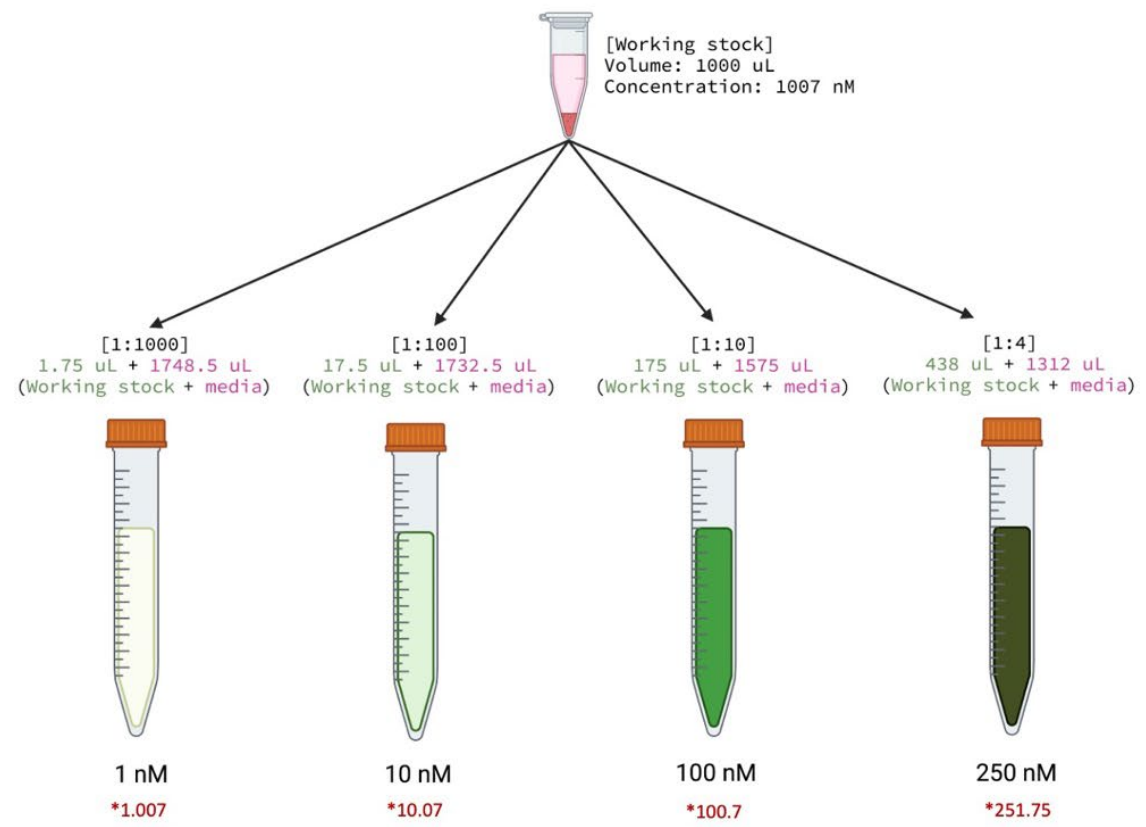

Figure 3: Schematic of steps taken for reconstitution of ghrelin (A) and preparation of ghrelin pre-treatment doses (B). Slight miscalculation during treatment preparation step 2 resulted in final ghrelin concentrations $0.007 \%$ higher than expected (precise values are marked with $a^{*}$ in red text) (B). Figure created using Biorender. 


\section{Block 2: LPS treatment (24-hours)}

A $20 \mathrm{uL}$ aliquot of LPS $(1,000,000 \mathrm{ng} / \mathrm{mL})$ was removed from the $-80^{\circ} \mathrm{C}$ freezer and allowed to thaw on ice for 30-45 minutes. Using fresh media as diluent, two-serial 1:100 dilutions were carried out in the cabinet for a final concentration of $100 \mathrm{ng} / \mathrm{mL}$ LPS. The 12-well plate from block 1 was placed back in the cabinet, media was removed, and fresh media with and without $100 \mathrm{ng} / \mathrm{mL}$ LPS was added in $750 \mathrm{uL}$ aliquots to each well. Plate was incubated at $37^{\circ} \mathrm{C}, 5 \% \mathrm{CO}_{2}$ for 24 -hours.

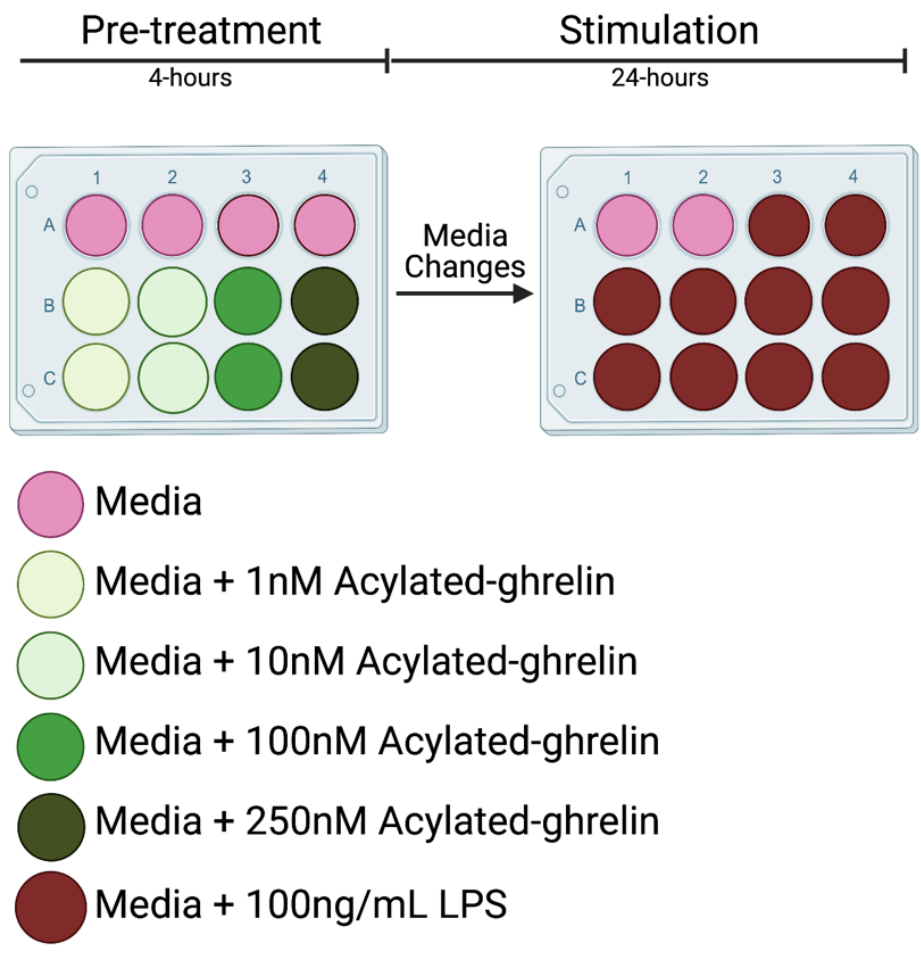

Figure 4: Sequential plate-mapping of treatments applied, across both treatment periods. Figure created using Biorender.

\section{Collection}

At the end of the $28^{\text {th }}$ hour, supernatants from the experimental plate were collected. 1.5mL Eppendorf tubes (4 per samples) were autoclaved, labelled, and stored either in the cabinet on ice ( 1 tube per sample for collection) or the $4^{\circ} \mathrm{C}$ fridge ( 3 tubes 
per sample for aliquoting). Using a 1,000uL pipette, 750 uL of supernatant were pipetted from each well into their respective tubes on ice. Tubes were transferred to a Legend Micro 21R table-top microcentrifuge (Thermoscientific) and centrifuged at 13,000 RPM for 15 minutes to remove any cellular debris $\left(4^{\circ} \mathrm{C}\right)$. While centrifuging was occurring, the experimental plate (still in the cabinet) was washed with cold 1x PBS for a total of 3 times with gentle agitation. PBS was aspirated, the plate was left to air-dry for 1 minute, covered with parafilm, and placed in the $-20^{\circ} \mathrm{C}$ freezer. Centrifuged samples were placed back on ice, and the top 700uL of supernatant was carefully extracted and equally split into 3 pre-chilled tubes. Once all samples were completed, they were placed in a sample box and stored in the $-80^{\circ} \mathrm{C}$ freezer until assaying.

\section{Quantifying Cytokines by ELISA}

Sandwich ELISA duoset kits (mus musculus) for interleukin-10 (catalog: DY417-05), interleukin-1 $\beta$ (catalog: DY401-05), and tumor necrosis factor- $\alpha$ (catalog: DY410-05) were purchased from R\&D systems (Bio-techne). Supernatants were thawed on ice for 45 minutes, and standards were reconstituted and diluted following manufacturers protocol. All reagents were made fresh ( $\sim 30$ minutes before use). 100uL of sample were added onto Nunc MaxiSorp ${ }^{\mathrm{TM}}$ 96-well flat-bottom ELISA plates (Invitrogen) in duplicate. All steps were followed as outlined in the manufacturers protocol, reagents were obtained from Ancillary Reagent Kit 2 (R\&D systems, catalog: DY008). Absorption was measured using iMark microplate reader (Bio-Rad) at 470nm with a 540nm filter. Optical imperfections of the plate were corrected for by subtracting the average of blank wells from each sample. 


\section{Cytokine concentrations were calculated by plotting the average measured absorbance}

\section{of the duplicate-sample on a 7-pt standard serial dilution of known concentrations.}

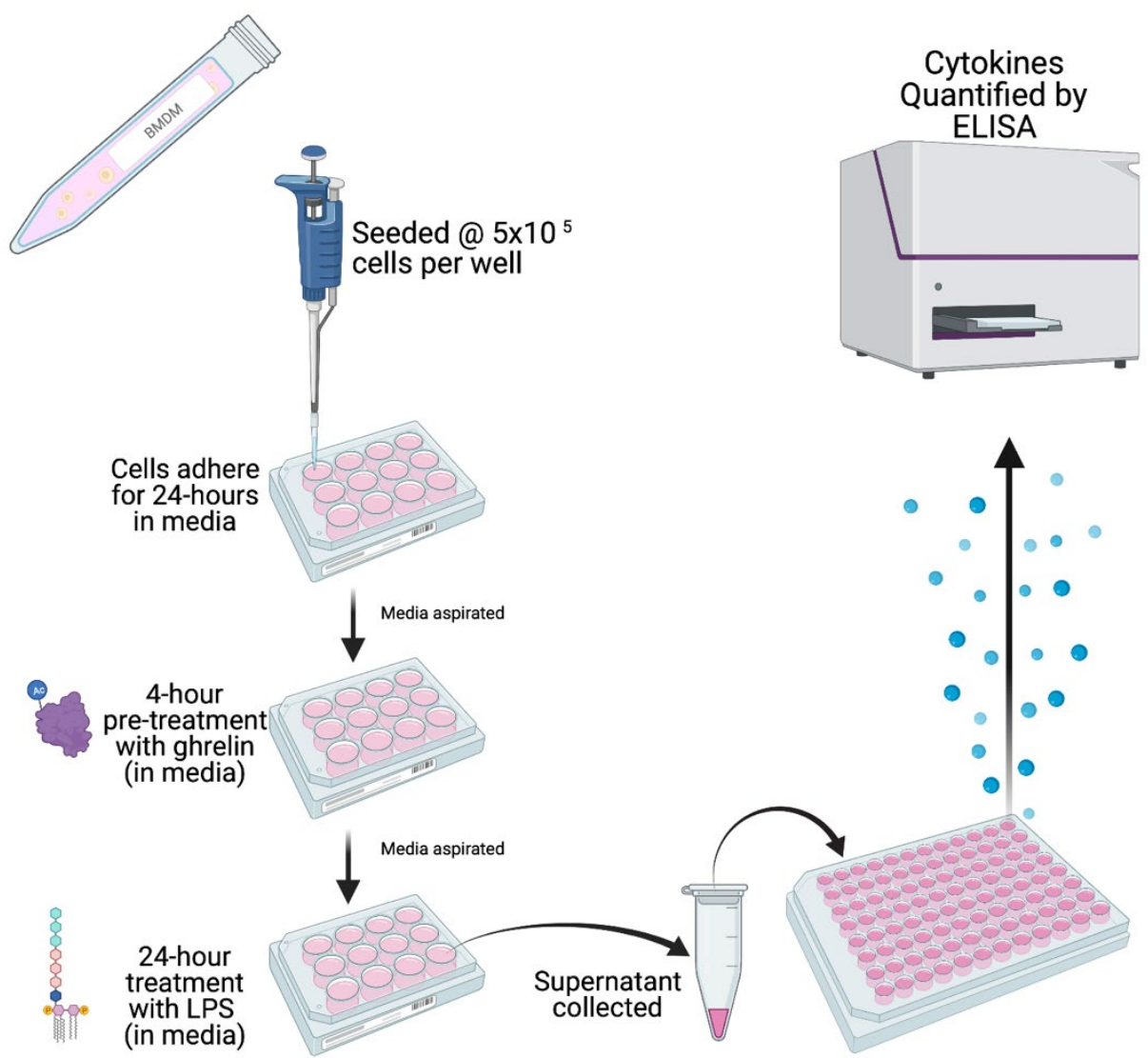

Figure 5: cells are seeded at a density of 500,000 per well and allowed to adhere to the plastic for 24-hour prior to experimentation. On hour 0 , cells are incubated in the presence or absence of various acyl-ghrelin doses (ranging from 1-250nM) made-up in cell-culture media. At the end of hour 4, media is removed from the wells using a 1,000 uL pipette, and fresh media is added containing LPS at a concentration of $100 \mathrm{ng} / \mathrm{mL}$. Supernatant is collected at the end of hour 28 , centrifuged at 12,000 RPM for 15 minutes $\left(4^{\circ} \mathrm{C}\right)$, split into aliquots, and stored at $-80^{\circ} \mathrm{C}$ until assaying. IL10, IL-1 $\beta$, and TNF- $\alpha$ were quantified by sandwich ELISA, R\&D duoset kits. Figure created using Biorender. 


\section{Quantifying Cytokines by Luminex MAGPIX}

Alternatively, cytokines were quantified using a custom ProcartaPlex Multiplex Immunoassay from Invitrogen (Cat. PPX-04-MXDJX3N, analytes: TNF- $\alpha$, IL-10, IL-1 $\beta$, and IP-10 or cat. PPX-04-MXCE4DN with analytes: TNF- $\alpha$, IL-10, IL-1 $\beta$, and IL-6). Supernatants were thawed on ice for 45 minutes, and standards were reconstituted and diluted following manufacturers protocol. All reagents were made fresh ( 30 minutes before use). 50 uL of sample was added onto 96-well flat-bottom ELISA plates (Thermofisher) in duplicate. All steps were followed as outlined in the manufacturers protocol, using a magnetic plate-holder. Absorbances were measured using xMap hardware and analyzed

on XPONENT software. 5-parameters fit was chosen for calculating concentration from MFI. Analytes IL-6 and IP-10 were above the upper limits of detection, data not shown.

\section{Statistical Analyses}

All statistical analyses were performed using Prism 9 (9.2.0; build 283). All ANOVAs were conducted at the $5 \%$ level of significance. P-values were adjusted using Sïdák's multiple comparisons correction. 


\section{Studies}

Study 1: Ghrelin degrades in cell-culture media containing foetal bovine calf serum Other studies have demonstrated that two nanomoles ( $2 \mathrm{nM}$ ) of acylated ghrelin is subject to degradation by butyrylcholinesterase and carboxylesterase when incubated at $37^{\circ} \mathrm{C}$ in human and rat serum, respectively (De Vriese et al., 2004). Recently, des-acyl ghrelin (the inactive form of ghrelin) has been shown to induce proliferative changes in carcinoma cell lines (Delhanty et al., 2012), potentially mediated by antagonistic actions on the GHSR-1a (Delhanty et al., 2012). Therefore, investigations that examine the role of acyl-ghrelin should consider whether their experimental model alters ghrelin's isoform. The purpose of this experiment is to evaluate if foetal bovine calf serum, a constituent of cell-culture media used in future experimentation, affect the levels of acyl-ghrelin during the 4-hour pre-treatment protocol.

We incubated $1.5 \mathrm{nM}$ of active peptide in cell-culture media for 4 -hours at $37^{\circ} \mathrm{C}$ with and without the addition of methyl arachidonoyl fluorophosphonate (MAFP), an irreversible serine-hydrolase inhibitor. Repeated sampling was carried out at 30 minutes, 1 hour, 2 hours, 3 hours, and 4 hours to assess the degradation of acyl-ghrelin over time. Samples were assayed by ELISA for acyl- and total ghrelin isoforms. ELISA kits were purchased from MilliporeSigma (EZGRA-90K and EZGRT-91K for acyl- and total ghrelin, respectively). Manufacturer's protocol was followed for every step. Absorption was measured using iMark microplate reader (Bio-Rad) at 470nm with a 540nm filter. Optical imperfections of the plate were corrected for by subtracting the average of blank wells 
from each sample. Data is converted to concentration and is plotted in duplicate using Prism.

Study 2: Serum-free and serum-containing culture media

To our knowledge, serum-starvation is a commonly used procedural step in cellculture assay experiments to control for heterogeneous cell cycles and metabolic processes (M. Chen et al., 2012) and to limit the effect of residual cytokines/hormones remaining in the serum (Rashid \& Coombs, 2019). The purpose of this experiment is to determine if foetal bovine calf serum has direct effects on cytokine responses from LPSstimulated BMDMs pre-treated with and without ghrelin.

To evaluate if serum has a confounding effect on the current model, we ran two experiments in parallel. In the first experiment $(n=2)$, BMDMs were incubated in the presence or absence of $10 \mathrm{nM}$ acyl-ghrelin for 4-hours, followed by a 24-hour LPS stimulation using either $1 \mathrm{ug} / \mathrm{mL}$, or $100 \mathrm{ng} / \mathrm{mL}$. Apart from cell-culture media being devoid of foetal bovine calf serum, the second experiment was identical $(n=2)$. Cytokines were quantified by Luminex, and data was plotted in Prism.

Study 3: Ghrelin modulates TLR4- but not TLR3-signaling

It has recently been shown that some macrophages downregulate their cytokine production in response to the bacterial pathogen LPS when pre-treated with various doses of acyl-ghrelin. BMDMs respond to the TLR3-agonist, polyinosinic:polycytidylic (poly $(\mathrm{I}: \mathrm{C})$ ), triggering NF- $\kappa \mathrm{B}$ and IRF3 signalling pathways leading to the expression and secretion of many pro-inflammatory cytokines. We wanted to test whether the effect of acyl-ghrelin observed in study 2 was applicable to virus-mediated macrophage responses 
(i.e., TLR3-dependent). High molecular weight (HMW) poly $(\mathrm{I}: \mathrm{C})$ has been shown to potently activate macrophages at doses ranging from $10 \mathrm{ng} / \mathrm{mL}-1 \mathrm{ug} / \mathrm{mL}$ (Ahmed et al., 2019). The purpose of this experiment is to assess if ghrelin augments TLR3-dependent signaling. We stimulated BMDMs $(\mathrm{n}=4)$ with LPS $(100 \mathrm{ng} / \mathrm{mL})$ or poly $(I: C)(100 \mathrm{ng} / \mathrm{mL})$ with and without 4-hour pre-treatment with ghrelin (10 nM). Cytokines were quantified by Luminex, and data was plotted in Prism.

Study 4: Various doses of ghrelin modulate cytokine responses to TLR4 induction

To date, investigations on the anti-inflammatory role of ghrelin have experimented with varying doses of the active peptide, the result of which is also variable. It has been shown that $10 \mathrm{nM}$ and $100 \mathrm{nM}$ doses significantly augmented cytokine production in LPS-stimulated RAW 264.7 cells, and $500 \mathrm{nM}$ did not produce any significant changes in BMDMs. The purpose of this experiment is to identify a dose, or range of doses of ghrelin that directly modulates cytokine responses to LPS $(100 \mathrm{ng} / \mathrm{mL})$ in BMDMs.

Clinical investigations of human populations have demonstrated a profound sex difference of many chronic inflammatory diseases, and these differences have been associated with sex-steroid signaling and X-linked genes. Recently, in vitro sex-differences in response to LPS have been demonstrated in astrocytes, but no data is available on sexdifferences in BMDMs. As such, study 4 has a second purpose - to evaluate if macrophage sex influences responses to LPS.

BMDMs from male $(n=4)$ and female $(n=5)$ mice were incubated in the presence or absence of acyl-ghrelin (1, 10, 100, and $250 \mathrm{nM})$ for 4-hours, followed by 24-hour 
stimulation with LPS (100 ng/mL). Supernatants were collected, cytokines were quantified by ELISA, and data was plotted in Prism.

Study 5: 250 nM ghrelin augments cytokine responses to LPS in male macrophages We demonstrated a robust effect of acyl-ghrelin (250 nM) to augment cytokine responses to LPS (100 ng/mL) in study 4 , and as well, this effect was seemingly absent from female macrophages. We wanted to continue experimentation with ghrelin (250 $\mathrm{nM}$ ) on BMDMs from male and female mice to increase statistical power. As such, the purpose of this experiment is to directly test the interaction of sex with pre-treatment (i.e., if the effect of ghrelin is dependent on the sex of the donor mouse).

BMDMs from male $(n=7)$ and female $(n=6)$ mice were incubated in the presence of absence of acyl-ghrelin (250 nM) for 4-hours, followed by 24-hour stimulation with LPS (100 ng/mL). Supernatants were collected, cytokines were quantified by ELISA, and data was plotted in Prism.

\section{Results}

Study 1: Determination of acyl-ghrelin stability in $37^{\circ} \mathrm{C}$ serum

The current thesis sought to determine if ghrelin directly affects cytokine responses in vitro. Ghrelin is known to degrade rapidly to desacyl-ghrelin once secreted into circulation (Müller et al., 2015) in mice, humans, and cows. Ex vivo growth, maintenance, and maturation of cells is achieved through the application of cell-culture media - a cocktail of mitogens and nutrients. Fetal bovine calf serum (FBS) is a component of cell-culture media provided as a supplement to support the viability of eukaryotic cells. 
However, FBS has been shown to contain hydrolase activity (Dafferner et al., 2017). Of concern were a group of enzymes known as esterases which use water to break the esterase bond holding acyl-ghrelin together. As such, we first needed to determine if cell culture media would influence acyl-ghrelin stability during the pre-treatment protocol described in the methods section. Here, a known concentration of acyl-ghrelin was added to cell-culture media and left to incubate in a $37^{\circ} \mathrm{C}$ oven for 30 minutes, 1 hour, 2 hours, 3 hours, or 4 hours in the presence or absence of methyl arachidonoyl fluorophosphonate (MAFP; a potent hydrolase inhibitor). After the $4^{\text {th }}$ hour, samples were assayed by ELISA for acyl-ghrelin and total ghrelin concentrations.
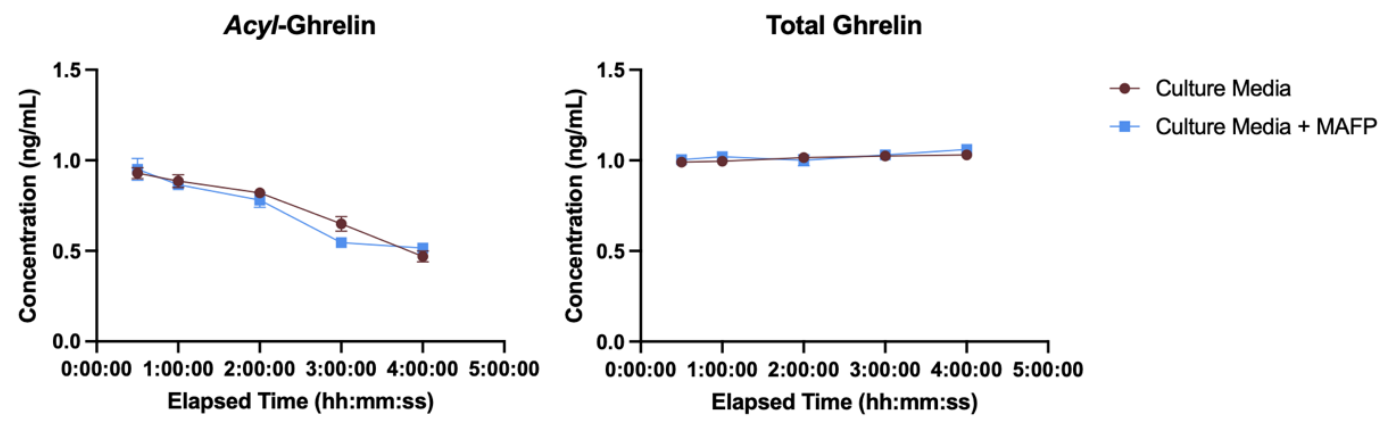

Figure 6: $5 \mathrm{ng} / \mathrm{mL}$ of reconstituted acyl-ghrelin (1.5 nM) was aliquoted onto a 24-well cell-culture plate in duplicate at pre-determined time points with and without MAFP (irreversible serine hydrolase inhibitor). 24-well plate was incubated at 37oC, representing experimental conditions of subsequent studies. Absorbance measured in duplicate with iMark and converted to concentration by fitting a 6-pt serial dilution of ghrelin concentration ranging from $0.15-$ $10 \mathrm{ng} / \mathrm{mL}$. Data plotted as percentage of concentration at time $=0$.

Results from this experiment show that acyl-ghrelin concentrations decreased over time, with a $35.33 \%$ loss at 4 hours. Results did not change with the addition of MAFP, suggesting that the mechanism of degradation of acyl-ghrelin in vitro is not hydrolase dependent. Total ghrelin concentrations remained constant, and this suggests that acyl-ghrelin is degrading into desacyl-ghrelin. It is possible that other degradation 
mechanisms exist; it has been shown that carboxypeptidases and endopeptidases can rapidly degrade acyl-ghrelin through proteolytic cleavage (Alper, 2021; Satou et al., 2011). These data demonstrate that acyl-ghrelin concentrations persist in cell culture media during the 4-hour prescribed pre-treatment incubation.

Study 2: Serum-free and serum-containing culture media

To begin investigation into ghrelin's capacity to directly augment cytokine secretion, we tested a $10 \mathrm{nM}$ dose from the publication by Waseem et al. (2008). BMDMs were incubated in the presence or absence of $10 \mathrm{nM}$ acyl-ghrelin for 4-hours, followed by a 24-hour LPS stimulation using either $1 \mathrm{ug} / \mathrm{mL}$, or $100 \mathrm{ng} / \mathrm{mL}$. In their publication, RAW 264.7 cells were 'serum-starved' prior to acyl-ghrelin treatment; although the authors do not discuss the importance of this step, we chose, for comparative reasons, to include groups that had been serum-starved and groups that had not. To our knowledge, serumstarvation is a commonly used procedural step in cell-culture assay experiments to force proliferating cells into a quiescent state (M. Chen et al., 2012) and to limit the effect of analytical interference caused by variability in serums composition (Rashid \& Coombs, 2019). 


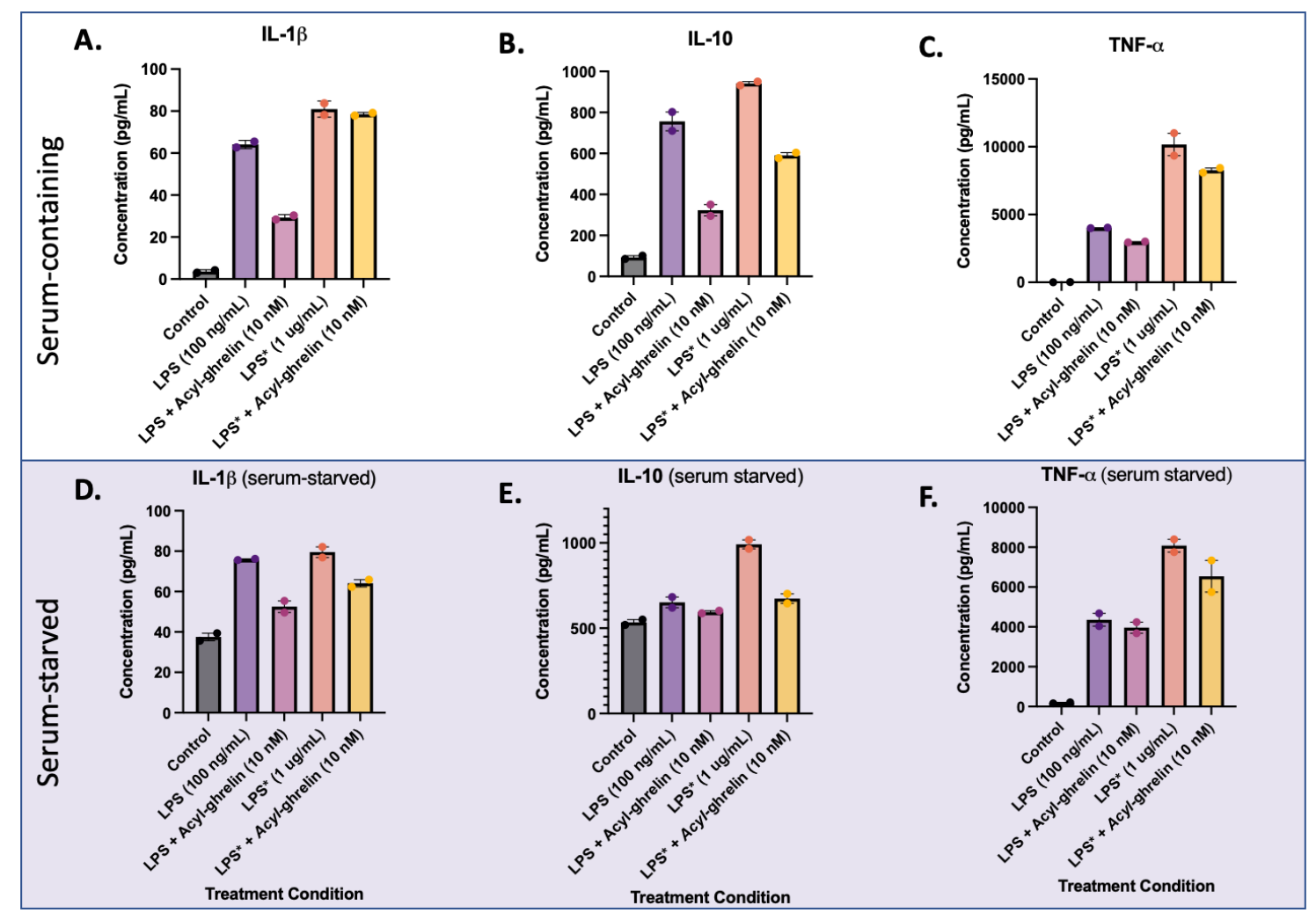

Figure 7: BMDMs from male femurs were incubated in serum-containing or serum-free cell-culture media for 12-hours, and then pre-treated with $10 \mathrm{nM}$ acyl-ghrelin for 4-hours, followed by 24-hour TLR4 induction at two different doses of LPS: low LPS (100 $\mathrm{ng} / \mathrm{mL})$, or high LPS (1 ug/mL). Data represented as mean $+/$ - SE of $n=2$ independent experiment. Luminex equipment was used to quantify IL-1 $\beta(A, D), I L-10(B, E)$, and TNF- $\alpha(C, F)$.

Results from this study suggest that $10 \mathrm{nM}$ acyl-ghrelin does influence cytokine secretion in response to LPS activation, and this effect is seemingly most robust at a lower dose of LPS (100 ng/mL). As well, these data demonstrate an effect of serum-starvation IL-1 $\beta$ and IL-10 concentrations in the control and low-dose LPS groups are increased in comparison to their serum-containing counterparts (Figure 7, A, B, D, E). Given that BMDMs are terminally differentiated (i.e., not proliferating), the rationale for employing serum-starvation does not fit the current experimental necessity. 
Study 3: Ghrelin modulates TLR4- but not TLR3-signaling

BMDMs respond to the TLR3-agonist, polyinosinic:polycytidylic (poly $(\mathrm{I}: \mathrm{C})$ ), triggering NF-KB and IRF3 signalling pathways leading to the expression and secretion of many pro-inflammatory cytokines. We wanted to test whether the effect of acyl-ghrelin observed in study 2 was applicable to virus-mediated macrophage responses (i.e., TLR3dependent). High molecular weight (HMW) poly (I:C) has been shown to potently activate macrophages at doses ranging from $10 \mathrm{ng} / \mathrm{mL}-1 \mathrm{ug} / \mathrm{mL}$ (Ahmed et al., 2019). To assess if ghrelin augments TLR3-dependent signaling, we stimulated BMDMs with LPS (100 $\mathrm{ng} / \mathrm{mL})$ or poly $(\mathrm{I}: \mathrm{C})(100 \mathrm{ng} / \mathrm{mL})$ with and without 4-hour pre-treatment with ghrelin (10 $\mathrm{nM})$.

A.

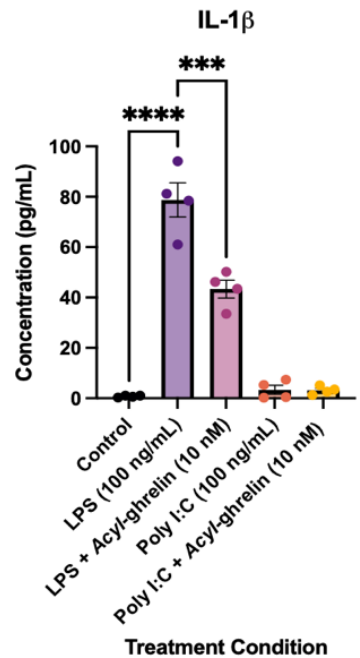

B.

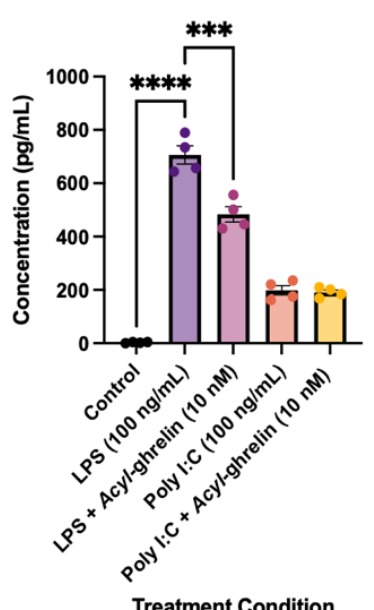

c.

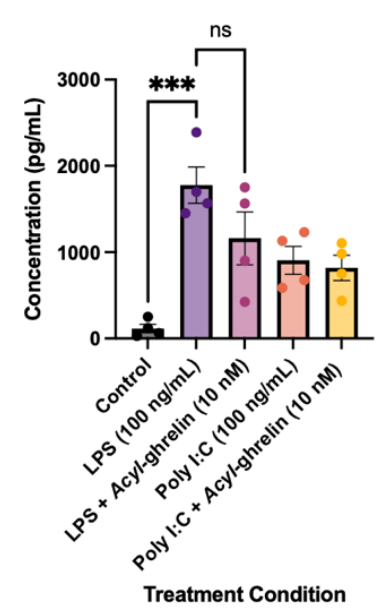

Figure 8: BMDMs from male C57BL/6J femurs were pre-treated for 4-hours with $10 \mathrm{nM}$ acyl-ghrelin prior to 24-hour stimulation with either the TLR4 agonist LPS $(100 \mathrm{ng} / \mathrm{mL})$ or the TLR3 agonist poly (I:C) $(100 \mathrm{ng} / \mathrm{mL})$. IL-16 (A), IL-10 $(B)$, and TNF- $\alpha(C)$ were quantified by custom 4-plex assays (Invitrogen) on Luminex equipment in duplicate. Average absorbance was converted to concentration by 5P-fitting a serial dilution of known concentration for the analytes. Data are represented at mean $+/$ - SE for $n=4$ independent experiment. One-way ANOVA was conducted in Prism at the $5 \%$ level of significance with post-hoc multiple paired T-tests and Šidáks correction. ${ }^{*} p<0.05{ }^{* *} p<0.01{ }^{* * *} p<0.001$ $* * * * p<0.0001$

These data demonstrate that 4-hour incubation with 10nM acyl-ghrelin significantly reduced IL-10 $(p=0.004, t=6.1, d f=9)$ concentrations in the supernatants of 
BMDMs following 24-hour activation with LPS (100 ng/mL), but not at an identical concentration of poly (I:C) (B). As well, the difference of IL-1 $\beta$ concentration in supernatants between pre-treated and not pre-treated was statistically significant $(p=0.0006, t=5.6, d f=9)$ when BMDMs were activated with LPS (A). Poly $(I: C)$ and LPS elicited a strong TNF- $\alpha$ response, and pre-treatment with acyl-ghrelin tended to decrease the effects of LPS (C), although this was not statistically significant ( $p=0.14, t=2.0, d f=9)$.

Study 4: Various doses of ghrelin modulate the response to TLR4 induction

Varying doses of acyl-ghrelin have been reported in the literature to influence downstream-TLR4 induced secretions. Most supported are 10 and $100 \mathrm{nM}$ concentrations, and recently it has been shown that very high doses of $500 \mathrm{nM}$ acylghrelin failed to significantly alter cytokine profiles of BMDMs when given concomitantly with TLR4 agonists. Given that we have shown previously $10 \mathrm{nM}$ did produce a significant change in IL-10, and IL-1 $\beta$ approached significance, we wanted to identify if other doses of acyl-ghrelin would be effective. As well, given the sexual differentiation of immunity in the general population and the lack of published data including both sexes, we wanted to assess if sex affects in vitro responses. To accomplish this, we also completed a doseresponse study in BMDMs derived from female C57BL/6J femurs. 


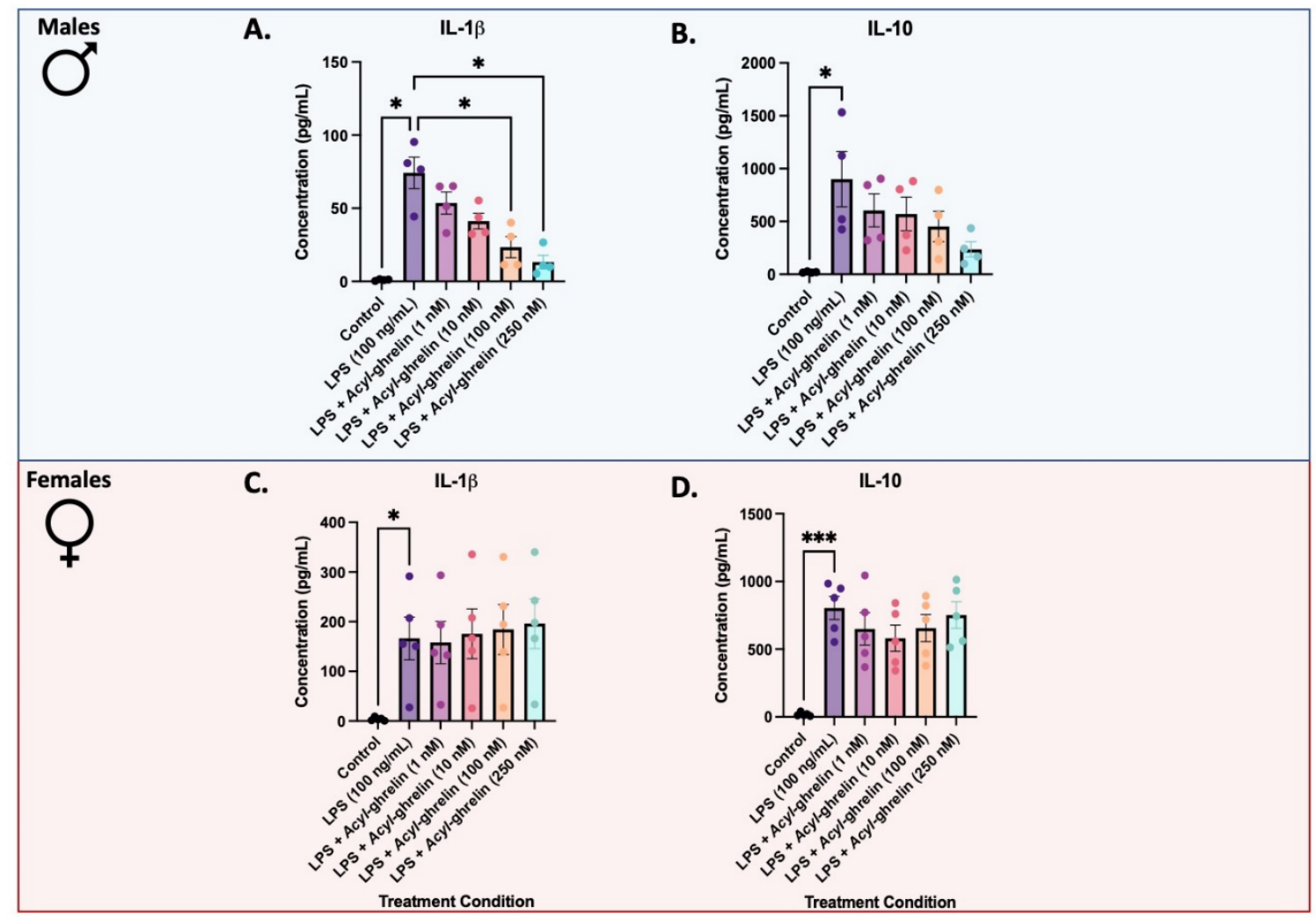

Figure 9: BMDMs from male and female C57BL/6J femurs were pre-treated with various doses of acyl-ghrelin for 4hours, followed by 24-hour LPS (100 $\mathrm{ng} / \mathrm{mL})$. Data represented as mean $+/$ - SE of $n=4$ independent experiments for males, and $n=5$ independent experiments for females. $I L-1 \beta(A, C)$, and $I L-10(B, D)$ were quantified by ELISA (R\&D Duoset) in duplicate. Average absorbance was converted to concentration $(\mathrm{pg} / \mathrm{mL})$ by $4 P$-fitting a serial dilution of known concentration for the primary antibody. One-way repeated measures ANOVA analysed was conducted in Prism at the $5 \%$ level of significance with post-hot multiple paired T-tests and Šidáks corrections. ${ }^{*} p<0.05{ }^{*} p<0.01$ $* * * p<0.001 * * * * p<0.0001$

Data from this study demonstrate a strong dose-response relationship between acyl-ghrelin and IL-1 $\beta(p=0.0002, F=26.37, d f=5) ; 100 \mathrm{nM}$ and $250 \mathrm{nM}$ doses resulted in significantly reduced secretion following 24-hour LPS ((p=0.025, $q=6.15, d f=3)$ and $(p=0.018, q=6.86, d f=3)$ respectively, A). A dose-response relationship can also be seen between acyl-ghrelin and IL-10 ( $p=0.03, F=9.896, d f=5, B)$, though considerably variable and not strong enough to result in any significant changes. Interestingly, these findings are seemingly exclusive to males as acyl-ghrelin dose did not correlate with changes in secretion of either IL-1 $\beta$ or IL-10 in females (C, D). 
Study 5: 250nM ghrelin augments cytokine responses to LPS in male macrophages

To address variability concerns and to further investigate the sex difference observed in study 4, we sought to repeat experimentation of the current model in both male and a female BMDMs using only acyl-ghrelin $(250 \mathrm{nM})$ for pre-treatment. As well, TNF- $\alpha$ thus far does not seem to be affected by $10 \mathrm{nM}$ acyl-ghrelin - however, the publication by Waseem and colleagues (2008) demonstrated a robust time-dependent suppression in RAW 264.7 cells. As such, we sought to determine if high-dose acyl-ghrelin $(250 \mathrm{nM})$ could augment secretion of TNF- $\alpha$ in response to LPS $(100 \mathrm{ng} / \mathrm{mL})$ in BMDMs.

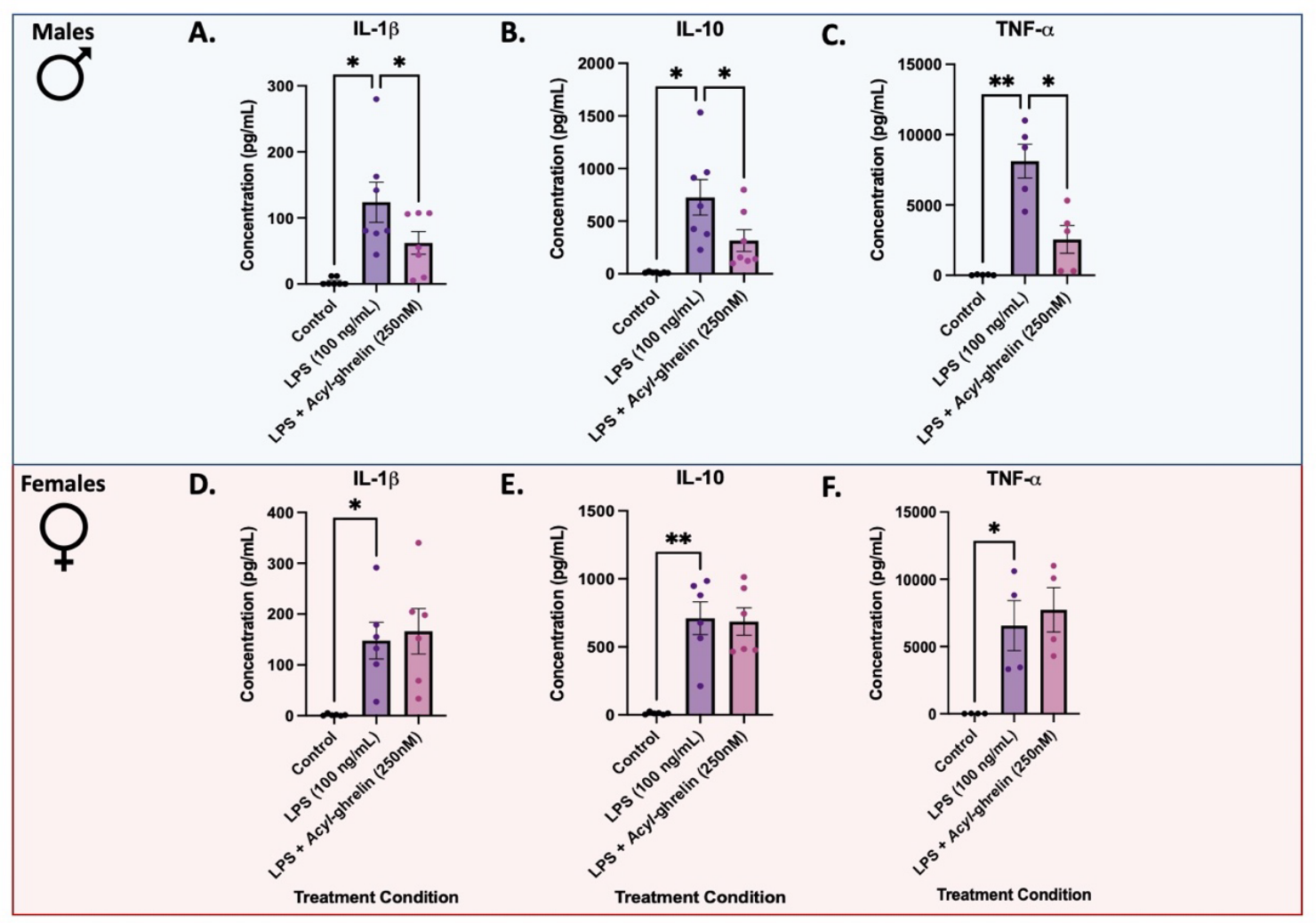

Figure 10: BMDMs from male and female C57BL/6J femurs were pretreated for 4-hours with $250 \mathrm{nM}$ acyl-ghrelin prior to 24-hour stimulation with LPS $(100 \mathrm{ng} / \mathrm{mL})$. IL-1B (A, D), IL-10 (B, E), and TNF- $\alpha(C, F)$ were quantified by ELISA (R\&D DuoSet) in duplicate. Average absorbance of duplicates $<10 \% \mathrm{CV}$ was converted to concentration (pg/mL) by $4 P$ fitting a serial dilution of known concentration for the primary antibody of each analyte. Data are represented as mean +/$S E$ for $n=7$ independent experiments for males, and $n=6$ independent experiments for females. ANOVA was conducted in Prism at the $5 \%$ level of significance with post-hoc multiple paired T-tests and Šidáks correction. ${ }^{*} p<0.05{ }^{* *} p<0.01$ $* * * p<0.001 * * * * p<0.0001$ 
Our results here demonstrate suppression of IL-1 $\beta(p=0.03, q=3.170, d f=6), I L-10(p=0.01$, $q=3.968, d f=6)$, and TNF- $\alpha(p=0.04, q=3.360, d f=4)$ in response to LPS $(100 \mathrm{ng} / \mathrm{mL})$ when pre-treated with acyl-ghrelin (250 nM) in BMDMs derived from males (A, B, C). This effect is absent in BMDMs derived from females (D, E, F).

Reactivity to acyl-ghrelin pretreatment

Evidence in the literature suggests that males are more reactive to acyl-ghrelin treatment compared to females (Farman et al., 2016). We analyzed the current data set for differences in cytokine response between male and female BMDMs. Two-way ANOVA revealed no significant main-effect of sex, however a significant interaction between sex and treatment condition can be observed for TNF- $\alpha(p=0.04, F=3.640, d f=2)$. The difference observed in TNF- $\alpha$ concentrations between pretreated females and males approached significance $(p=0.06, t=2.164, d f=7)$. As well, differences in IL-10 concentrations between pre-treated females and males was found to be significant $(p=0.02, t=2.539, d f=7)$.

\section{Discussion}

Several groups show that acyl-ghrelin directly influences macrophage function, with significant effects on cytokine secretion and disease prognosis (Corrêa da Silva et al., 2019; Dixit et al., 2004; Waseem et al., 2008). In keeping with this, our data supports a direct role of acyl-ghrelin in augmenting cytokine responses to LPS in BMDMs. In this 
series of studies, we demonstrate the following: 1) when BMDMs are pretreated with acyl-ghrelin for 4-hours, there is a dose-response decrease in IL-1 $\beta, I L-10$, and TNF- $\alpha$ secretion following 24-hour activation with LPS (100 ng/mL). 2) BMDMs from independent donors vary in their response magnitude, although not statistically significant. 3) Differential pretreatment effect of acyl-ghrelin is sex-dependent. We provide supporting evidence to the current body of literature that suggests acyl-ghrelin has a direct immuno-modulatory role on macrophages. However, in contrast to the findings of Waseem et al. (2008) which reported increases in IL-10, our data suggest that GHSR-1a signaling suppresses IL-10 secretion. This is in line with the work of Ziko and colleagues (2018) who found a suppression of plasma IL-10 in Wistar rats treated with acyl-ghrelin prior to LPS injection. In consultation with the literature, we will next discuss the biological basis of our findings and integrate this knowledge with the on-going efforts in the field.

\section{Potential Mechanisms - pAMPK}

In response to LPS, macrophages reorganize their cytoplasm and mitochondria to modulate energy production and substrate biosynthesis. In this M1 phenotypic-state, large amounts of arginine are used in the production of microbicidal nitric oxide (NO), aerobic glycolysis in the cytoplasm becomes the main source of ATP for phagocytosis, and by-products of glycolysis are used as precursors in the pentose phosphate pathway (Batista-Gonzalez et al., 2020). Underlying metabolic changes are crucial signaling cascades that result in numerous kinase and phosphatase activation; interrupting, or 
altering these cascades has profound effects on the metabolism and activation of macrophages and thus influences their capacity to carry out their immune function. In murine macrophages, prominent calcium influx is known to activate CaMKK $\beta$-AMPK signaling pathways, resulting in increased concentrations of phosphorylated-AMPK in the cytoplasm (X. Liu et al., 2016). The pAMPK protein is a crucial regulator of cellular metabolism, and high concentrations of this protein are known to alter mitochondrial membrane potentials in macrophages. In fact, changes in mitochondrial membrane potentials are necessary for appropriate metabolic responses that support effector function (Ramond et al., 2019). Increases in PAMPK are proportional to decreases in acetyl-coenzyme A carboxylase (ACC) activity in murine macrophages (Mills et al., 2016), and ACC is necessary for de novo fatty-acid synthesis used in the production of inflammatory mediators. As a result of increased pAMPK, LPS-stimulated macrophages are impaired in their ability to produce inflammatory mediators and to adapt their mitochondrial membranes to support shifts in the oxidative phosphorylation system. IL$1 \beta$ is one such pro-inflammatory cytokine that requires reorganization of the electrontransport chain - succinate induces IL-1 $\beta$ through hypoxia-inducible factor-1 $\alpha$ (HIF-1 $\alpha$ ) (Tannahill et al., 2013), which is the master regulator of transcriptional responses to hypoxia (such as when M1 macrophages exhaust oxygen supply during aerobic glycolysis and ROS production). Anti-inflammatory cytokines like IL-10 strongly suppress IL-1 $\beta$ release, and inhibit TNF- $\alpha$ expression and secretion, and rapidly phosphorylate AMPK (Sag et al., 2008). Inhibition of AMPK $\alpha$ (the catalytic subunit that interacts with the mTOR signal TSC2) restores IL-1 $\beta$ and TNF- $\alpha$ production in the presence of IL-10, suggesting that 
pAMPK is a crucial mediator of intracellular inflammatory signaling. For an in-depth review of how AMPK interacts with NF-אB signaling please see (Salminen et al., 2011). Lastly, macrophages self-regulate and shift between pro-inflammatory and antiinflammatory states (M1 and M2 phenotypes, respectively) depending on the signaling environment. In the presence of anti-inflammatory stimuli, macrophages reorganize their cytoplasm and mitochondria to support oxidative phosphorylation and lipid synthesis. It has been shown that PAMPK is necessary for the metabolic reprogramming accompanying the phenotypic shift in murine macrophages during the transition between inflammation and resolution (Ip et al., 2017; Nieves et al., 2016).

In macrophages, ligation of TLR4 induces NF- $\mathrm{KB}$ activation and translocation of the p65 subunit into the nucleus where it induces transcription of inflammatory genes. Secreted TNF- $\alpha$ has a positive autocrine effect, binding to its receptor (TNFR) reinforces NF-KB signaling, thus establishing a feedforward loop. TNF- $\alpha$ also induces the transcription of Sp1, a transcription factor necessary to produce IL-10. Binding of IL-10 to IL-10R, in turn activates STAT3, inducing anti-inflammatory genes such as suppressor of cytokine signaling 1 (Socs1). SOCS1 is an autofeedback negative regulator of TLR4 signaling that directly associates with IRAK 1 to suppress NF- kB signaling (Kinjyo et al., 2002). Thus, IL-10 is a counterbalance to TNF- $\alpha$. In macrophages, autocrine IL-10 is suppressed by pAMPK through its inhibitory action on TNF- $\alpha$ secretion (Baseler et al., 2016).

Typically, G-protein coupled receptor (GPCR) action results in intracellular calcium influx. In a plethora of cell types, ligation of GHSR-1a (which is a GPCR) results in 
considerably more calcium influx than the typical GPCR (Erriquez et al., 2009), due to the release of intracellular calcium stores and the activation of at least two surface calcium channels. In T cells, the intracellular effect of ghrelin on cytoplasmic-calcium concentrations is similar to T-cell chemokines (Mathur et al., 2021), suggesting that immune cells are highly reactive to acyl-ghrelin. Da Silva and colleagues showed that 18hours of $500 \mathrm{nM}$ acyl-ghrelin resulted in significant changes in oxygen consumption and mitochondrial membrane potential in LPS-stimulated BMDMs. Waseem and colleagues demonstrated that acyl-ghrelin inhibits the translocation of the p65 subunit of the NF-KB complex in RAW 264.7 cells - this is likely to be dependent on AMPK-SIRT1-NF-kB signaling (see (Salminen et al., 2011)). Wang and colleagues (2009) provided evidence that acyl-ghrelin increases MPK-1 expression in kuppfer cells, a MAPK phosphatase that negatively regulates inflammation and is indirectly regulated by PAMPK-p38 interplay (Wang, 2009). In neurons, Andrews et al. showed that acyl-ghrelin treatment induced mitochondrial proliferation, increased oxygen consumption, activated AMPK, and increased UCP2 expression (Andrews et al., 2008). It is clear from our data, and from the work of others, that acyl-ghrelin significantly influences cytokine secretion, and this effect is likely due to GHSR-1a-dependent calcium induced CaMKK $\beta$-AMPK signaling pathways. From this framework, one would expect 4-hours pretreatment with ghrelin would result in significant pAMPK concentrations in the cytoplasm; generally, pAMPK turns on energy producing processes, and turns off energy consuming processes. As such, the energyconsuming process of TLR4 ligation would be confronted with a metabolic program incompatible with the demands of proinflammation. The measurable outcome of such 
confrontation would be an impaired cytokine response - TNF- $\alpha$, IL-10, and IL-1 $\beta$ would be secreted less than their LPS-stimulated controls.

Pre-treatment with ghrelin had no effect on TLR3-mediated activation. It has been shown that BMDMs activated with $\mathrm{HMW}$ poly $(\mathrm{I}: \mathrm{C})$ retain OXPHOS capacity in the mitochondria for ATP production (Ahmed et al., 2019), whereas LPS-mediated activation does not require maintenance of OXPHOS. In fact, it has been shown that activation with LPS $(100 \mathrm{ng} / \mathrm{mL})$ results in a loss of basal OXPHOS activity in the mitochondria. Interestingly, it is currently thought that GHSR signaling results in increased OXPHOS activity via its association with ACC and CPT1, turning up fatty acid metabolism. Corrêa da Silva and colleagues (2019) pre-treated BMDMs with ghrelin (500 nM) and demonstrated prominent changes in mitochondrial membrane potential, and an inhibition of LPSinduced glycolysis. Therefore, ghrelin signaling biases energy production towards the mitochondria to increase OXPHOS, a retained metabolic component of TLR3- but not TLR4-dependent activation.

\section{Sex differences}

BMDMs originate in the bone-marrow from hematopoietic stem cells (HSCs), containing both myeloid and lymphoid differentiation potential (Yamamoto et al., 2013). In vivo, progenitors from the bone marrow enter circulation through vascular niches of the bone where they encounter mitogenic and chemotactic signals that direct its fate and resident destination. HSCs express receptors for sex steroids, namely estrogens (ER $\alpha$ ) and androgens (AR) (Ribas et al., 2011). Importantly, this suggests that HSCs/progenitors (and 
other immune cells) can be influenced by circulating sex hormones in vivo. As well, plasma estrogen locally circulates in bone vasculature, and in female mice estrogen treatment increases proliferation rate of bone-marrow HSCs (Nakada et al., 2014). Signaling via ER $\alpha$ leads to epigenetic changes by binding of the regulatory and enhancer elements leading to the formation of chromatin loops (Cvoro et al., 2006). Nuclear ER $\alpha$ can dimerize with coactivators and influence the expression of downstream target genes, such as the welldocumented ER $\alpha-N F-\kappa B$ relationship (Sas et al., 2012), suggesting that estrogen can directly influence signaling modalities involved in inflammation. The $E R \alpha$ is encoded by the Esr1 gene and is negatively regulated through autocrine feedback - premenopausal women express ER $\alpha$ significantly less than men and postmenopausal women in numerous tissues, including myeloid cells (but not lymphoid cells; (Phiel et al., 2005)L. This implies that bone marrow progenitors are subject to fluctuating estrogen levels in vivo, with potential contributions to in vitro responses via epigenetic regulation of genes involved in inflammation.

BMDMs from males and females also differ in their chromosome profiles - males harbor one $\mathrm{x}$ and one $\mathrm{y}$ chromosome, while females harbor two potentially different $\mathrm{X}$ chromosomes. It is now known that immune cells retain intrinsic sex differences in vitro (for a complete review, please refer to (Klein \& Flanagan, 2016)). To date, while the data on sexually despaired transcriptomics is limited for BMDMS, there are two studies to consider. In a transcriptomic study of BMDMs from male and female chickens (GarciaMorales et al., 2015), the authors demonstrated that female BMDMs express suppressor of cytokine signaling 1 (Soc1) 1.6-fold higher than males, and this difference was 
attributed to IFN-response genes located on a $W$ chromosome cluster. Birds and mice are genetically dissimilar in organization; however, it is likely that genomic imprinting on the regulation of cytokine signaling exists outside of avian species. In a powerful quantitative trait loci study of BMDMs from male $(n=114)$ and female $(n=93)$ C57BL/6J mice, the authors reported the expression of 6,700 transcripts with significant differences under basal conditions (Bhasin et al., 2008). It is important to note here, that like the current experimental design, these BMDMs were cultured ex vivo and thus not under the influence of fluctuating sex hormones.

GHSR-1a expression is regulated by $\beta$-estradiol - in humans, an estrogenresponsive element has been identified between -309 and the start codon of the GHSR1a promotor region and increases in estrogen are associated with increases in surface GHSR-1a expression (Yin et al., 2014). Similar results have been reported in C57BL/6J mice, although the authors did not map the GHSR gene to identify the response element (Yasrebi et al., 2016). This is important because it suggests that in vivo estrogen exposure can have direct effects on GHSR-1a levels; a female mouse with high plasma estrogen at the time of sacrifice might harbor myeloid progenitors with increased GHSR-1a quantity in comparison to a female with lower plasma estrogen. This is one potential mechanism that explains the effects observed in females of the current thesis $-6 / 7$ female experiments showed no effect of ghrelin pretreatment, however, there was 1 female experiment (animal I.D. 54G) where $250 \mathrm{nM}$ ghrelin pretreatment decreased IL-1 $\beta$ by half, and increased IL-10 by more than double and TNF- $\alpha$ by $~ 10 \%$ (data not shown). During the titration experiment, $10 \mathrm{nM}$ ghrelin pretreatment resulted in a trend towards a 
significant decrease in IL-10 (Figure 9: D). It is possible that most of the female sample was in proestrus or estrus stages in their respective cycle on the day of sacrifice, when estradiol concentrations in the plasma are the lowest. The resulting BMDMs from lowestrogen females could harbor histone modifications (particularly methylations) that suppress GHSR expression (for a complete review of ER $\alpha$-mediated genomics, please see (Kovács et al., 2020)). When taken together, it is apparent that in vivo estrogen exposure is a variable of the current experimental design that was not factored in appropriately. However, this does provide a basis for explaining the variability observed in the cytokine responses of female BMDMs. For the current thesis, it is known that femurs used in the generation of BMDMs were collected on at least two different days. It is possible then, that ex vivo ER $\alpha$ and GHSR-1a surface protein quantities were influenced by in vivo estrogen exposure, potentially contributing to changes in TLR4 signal transduction pathways and ghrelin binding potential. Other groups have reported sex-dependent epigenetic aberrations in human pluripotent stem cells that have direct effects on cell growth and the expression of tumor-suppressor genes in vitro (Weissbein et al., 2017).

During embryogenesis, females randomly have one of their $X$ chromosomes inactivated through methylation mechanisms - a dose-compensation mechanism for maintaining approximately equal expression of X-linked genes between sexes. However, females inherit a paternal and a maternal X-chromosome, and thus benefit from increased X-linked diversity. Some proteins involved in NF-KB signalling are X-linked: interluekin-1 receptor-associated kinase 1 (IRAK-1), NF- KB essential modulator (NEMO), and Bruton's tyrosine kinase (BTK) (Spolarics, 2007). Klinefelter syndrome is an 
aneuploidy that presents in males with an extra $\mathrm{X}$ chromosome (i.e., $\mathrm{XXY}$ ) and as such, this population presents a unique way of evaluating the effect of sex chromsomes during inflammation (Sawalha et al., 2009). Strikingly, Klinefelter patients have an increased risk of autoimmune disease similar to that of women (Sawalha et al., 2009). Sex differences in immune responses have also been established in prepubertal children; girls suffer more severly from chronic inflammatory diseases (Casimir et al., 2010). When taken together this suggests that chromosome makeup effects immunity irrespective of sex steroid hormones, with potential consequences on immune signaling mechanisms.

Finally, macrophage polarization appears to be different between male and female mice - myocardial infiltrating macrophages from males express higher markers for M1 activation, while macrophages from females express higher markers for M2 (K. Li et al., 2009). It is possible that $X$-linked genes bias macrophage polarization towards $M 2$, a metabolic program that retains OXPHOS maintenance and thus is not likely to be signficantly affected by GHSR signaling.

\section{Conclusion and Future Direction}

We report, for the first time, a sex-dependent augmentation in cytokine secretion from LPS-stimulated BMDMs that were pre-treated with acyl-ghrelin. Our data are in keeping with the work of other research groups that have shown ghrelin-dependent changes in metabolic programming and inflammatory signaling pathways. There are limitations of the current study design that should be addressed in future work: 
1. The concomitant use of a GHSR-1a antagonist to demonstrate receptor-specific action should be included

2. Trunk blood from donor animals should be assayed for estrogen concentration, and this quantitation should be analyzed for associations with GHSR-1a transcripts in BMDMs

a. Alternatively, macrophages obtained from femurs from ovariectomized female mice would provide valuable insight into the effects of estrogen on the current experiment

3. A dose $x$ time matrix approach should be taken to identify the most efficacious exposure parameters for ghrelin pretreatment

In culmination, this work contributes to the growing body of evidence that implicates metabolic peptides in inflammatory processes - furthering our understanding of complex inflammatory diseases that interact with host-metabolism, such as obesity and cancercachexia in which a steady increase in inflammatory markers is often observed with a steady decline of ghrelin-mediated signaling (Alvarez-Castro et al., 2013; Terawaki et al., 2017). 


\section{References}

1. Abizaid, A., Liu, Z.-W., Andrews, Z. B., Shanabrough, M., Borok, E., Elsworth, J. D., Roth, R. H., Sleeman, M. W., Picciotto, M. R., Tschöp, M. H., Gao, X.-B., \& Horvath, T. L. (2006). Ghrelin modulates the activity and synaptic input organization of midbrain dopamine neurons while promoting appetite. Journal of Clinical Investigation, 116(12), 3229-3239. https://doi.org/10.1172/JCI29867

2. Adams, B., Nunes, J. M., Page, M. J., Roberts, T., Carr, J., Nell, T. A., Kell, D. B., \& Pretorius, E. (2019). Parkinson's disease: A systemic inflammatory disease accompanied by bacterial inflammagens. Frontiers in Aging Neuroscience, 10(JUL), 1-17. https://doi.org/10.3389/fnagi.2019.00210

3. Ahmed, D., Roy, D., Jaworski, A., Edwards, A., Abizaid, A., Kumar, A., Golshani, A., \& Cassol, E. (2019). Differential remodeling of the electron transport chain is required to support TLR3 and TLR4 signaling and cytokine production in macrophages. Scientific Reports, 9(1), 18801. https://doi.org/10.1038/s41598019-55295-4

4. Alper, B. J. (2021). Ghrelin proteolysis by insulin-degrading enzyme (preprint).

5. Alvarez-Castro, P., Pena, L., \& Cordido, F. (2013). Ghrelin in Obesity, Physiological and Pharmacological Considerations. Mini-Reviews in Medicinal Chemistry, 13(4), 541-552. https://doi.org/10.2174/1389557511313040007

6. Andrews, Z. B., Liu, Z. W., Walllingford, N., Erion, D. M., Borok, E., Friedman, J. M., Tschöp, M. H., Shanabrough, M., Cline, G., Shulman, G. I., Coppola, A., Gao, X. B., Horvath, T. L., \& Diano, S. (2008). UCP2 mediates ghrelin's action on 
NPY/AgRP neurons by lowering free radicals. Nature, 23(1), 846-851.

https://doi.org/10.1038/nature07181.UCP2

7. Aulock, S. Von, Deininger, S., Draing, C., Gueinzius, K., Dehus, O., \& Hermann, C. (2006). Gender Difference in Cytokine Secretion on Immune Stimulation with LPS and LTA. Journal of Interferon \& Cytokine Research, 26(12), 887-892. https://doi.org/10.1089/jir.2006.26.887

8. Barkan, A. L., Dimaraki, E. V., Jessup, S. K., Symons, K. V., Ermolenko, M., \& Jaffe, C. A. (2003). Ghrelin secretion in humans is sexually dimorphic, suppressed by somatostatin, and not affected by the ambient growth hormone levels. Journal of Clinical Endocrinology and Metabolism, 88(5), 2180-2184. https://doi.org/10.1210/jc.2002-021169

9. Baseler, W. A., Davies, L. C., Quigley, L., Ridnour, L. A., Weiss, J. M., Hussain, S. P., Wink, D. A., \& McVicar, D. W. (2016). Autocrine IL-10 functions as a rheostat for M1 macrophage glycolytic commitment by tuning nitric oxide production. Redox Biology, 10, 12-23. https://doi.org/10.1016/j.redox.2016.09.005

10. Batista-Gonzalez, A., Vidal, R., Criollo, A., \& Carreño, L. J. (2020). New Insights on the Role of Lipid Metabolism in the Metabolic Reprogramming of Macrophages. Frontiers in Immunology, 10. https://doi.org/10.3389/fimmu.2019.02993

11. Beenakker, K. G. M., Westendorp, R. G. J., De Craen, A. J. M., Chen, S., Raz, Y., Ballieux, B. E. P. B., Nelissen, R. G. H. H., Later, A. F. L., Huizinga, T. W., Slagboom, P. E., Boomsma, D. I., \& Maier, A. B. (2020). Men Have a Stronger MonocyteDerived Cytokine Production Response upon Stimulation with the Gram- 
Negative Stimulus Lipopolysaccharide than Women: A Pooled Analysis Including 15 Study Populations. Journal of Innate Immunity, 12(2), 142-153.

https://doi.org/10.1159/000499840

12. Bhasin, J. M., Chakrabarti, E., Peng, D.-Q., Kulkarni, A., Chen, X., \& Smith, J. D. (2008). Sex Specific Gene Regulation and Expression QTLs in Mouse Macrophages from a Strain Intercross. PLOS ONE, 3(1), e1435. https://doi.org/10.1371/journal.pone.0001435

13. Briggs, D. I., \& Andrews, Z. B. (2011). Metabolic Status Regulates Ghrelin Function on Energy Homeostasis. Neuroendocrinology, 93(1), 48-57. https://doi.org/10.1159/000322589

14. Cai, K. C., van Mil, S., Murray, E., Mallet, J. F., Matar, C., \& Ismail, N. (2016). Age and sex differences in immune response following LPS treatment in mice. Brain, Behavior, and Immunity, 58, 327-337. https://doi.org/10.1016/j.bbi.2016.08.002

15. Casimir, G. J. A., Mulier, S., Hanssens, L., Knoop, C., Ferster, A., Hofman, B., \& Duchateau, J. (2010). Chronic inflammatory diseases in children are more severe in girls. Shock, 34(1), 23-26. https://doi.org/10.1097/SHK.0b013e3181ce2c3d

16. Casimir, G. J. A., Mulier, S., Hanssens, L., Zylberberg, K., \& Duchateau, J. (2010). Gender differences in inflammatory markers in children. Shock, 33(3), 258-262. https://doi.org/10.1097/SHK.0b013e3181b2b36b

17. Chang, L., Zhao, J., Yang, J., Zhang, Z., Du, J., \& Tang, C. (2003). Therapeutic effects of ghrelin on endotoxic shock in rats. European Journal of Pharmacology, 473(2-3), 171-176. https://doi.org/10.1016/S0014-2999(03)01972-1 
18. Chen, M., Huang, J., Yang, X., Liu, B., Zhang, W., Huang, L., Deng, F., Ma, J., Bai, Y., Lu, R., Huang, B., Gao, Q., Zhuo, Y., \& Ge, J. (2012). Serum Starvation Induced Cell Cycle Synchronization Facilitates Human Somatic Cells Reprogramming. PLoS ONE, 7(4), e28203. https://doi.org/10.1371/journal.pone.0028203

19. Chen, Y., Zhang, Y., Zhao, G., Chen, C., Yang, P., Ye, S., \& Tan, X. (2016).

Difference in Leukocyte composition between women before and after menopausal age, and distinct sexual dimorphism. PLOS ONE, 11(9), 1-10. https://doi.org/10.1371/journal.pone.0162953

20. Cinti, S., Mitchell, G., Barbatelli, G., Murano, I., Ceresi, E., Faloia, E., Wang, S., Fortier, M., Greenberg, A. S., \& Obin, M. S. (2005). Adipocyte death defines macrophage localization and function in adipose tissue of obese mice and humans. Journal of Lipid Research, 46(11), 2347-2355.

https://doi.org/10.1194/jlr.M500294-JLR200

21. Corrêa da Silva, F., Aguiar, C., Pereira, J. A. S., de Brito Monteiro, L., Davanzo, G. G., Codo, A. C., Pimentel de Freitas, L., Berti, A. S., Lopes Ferrucci, D., Castelucci, B. G., Consonni, S. R., Carvalho, H. F., \& Moraes-Vieira, P. M. M. (2019). Ghrelin effects on mitochondrial fitness modulates macrophage function. Free Radical Biology and Medicine, 145(September), 61-66. https://doi.org/10.1016/j.freeradbiomed.2019.09.012

22. Currie, P. J., Mirza, A., Fuld, R., Park, D., \& Vasselli, J. R. (2005). Ghrelin is an orexigenic and metabolic signaling peptide in the arcuate and paraventricular nuclei. American Journal of Physiology - Regulatory Integrative and Comparative 
Physiology, 289(2 58-2), 353-358. https://doi.org/10.1152/ajpregu.00756.2004

23. Cvoro, A., Tzagarakis-Foster, C., Tatomer, D., Paruthiyil, S., Fox, M. S., \& Leitman, D. C. (2006). Distinct Roles of Unliganded and Liganded Estrogen Receptors in Transcriptional Repression. Molecular Cell, 21(4), 555-564. https://doi.org/10.1016/j.molcel.2006.01.014

24. Dafferner, A. J., Lushchekina, S., Masson, P., Xiao, G., Schopfer, L. M., \& Lockridge, O. (2017). Characterization of butyrylcholinesterase in bovine serum. Chemico-Biological Interactions, 266, 17-27. https://doi.org/10.1016/j.cbi.2017.02.004

25. De Vriese, C., Gregoire, F., Lema-Kisoka, R., Waelbroeck, M., Robberecht, P., \& Delporte, C. (2004). Ghrelin Degradation by Serum and Tissue Homogenates: Identification of the Cleavage Sites. Endocrinology, 145(11), 4997-5005. https://doi.org/10.1210/en.2004-0569

26. Delhanty, P. J. D., Neggers, S. J., \& van der Lely, A. J. (2012). Mechanisms in Endocrinology: Ghrelin: the differences between acyl- and des-acyl ghrelin. European Journal of Endocrinology, 167(5), 601-608. https://doi.org/10.1530/EJE-12-0456

27. Delporte, C. (2013). Structure and Physiological Actions of Ghrelin. Scientifica, 2013(Figure 1), 1-25. https://doi.org/10.1155/2013/518909

28. Dembiński, A., Warzecha, Z., Ceranowicz, P., Bielański, W., Cieszkowski, J., Dembiński, M., Pawlik, W. W., Kuwahara, A., Kato, I., \& Konturek, P. C. (2005). Variable effect of ghrelin administration on pancreatic development in young 
rats. role of insulin-like growth factor-1. Journal of Physiology and Pharmacology, 56(4), 555-570.

29. Dixit, V. D., Schaffer, E. M., Pyle, R. S., Collins, G. D., Sakthivel, S. K., Palaniappan, R., Lillard, J. W., \& Taub, D. D. (2004). Ghrelin inhibits leptin- and activationinduced proinflammatory cytokine expression by human monocytes and T cells. Journal of Clinical Investigation, 114(1), 57-66. https://doi.org/10.1172/jci21134

30. Erriquez, J., Bernascone, S., Ciarletta, M., Filigheddu, N., Graziani, A., \& Distasi, C. (2009). Calcium signals activated by ghrelin and D-Lys3-GHRP-6 ghrelin antagonist in developing dorsal root ganglion glial cells. Cell Calcium, 46(3), 197208. https://doi.org/10.1016/j.ceca.2009.07.003

31. Farman, H. H., Windahl, S. H., Westberg, L., Isaksson, H., Egecioglu, E., Schele, E., Ryberg, H., Jansson, J. O., Tuukkanen, J., Koskela, A., Xie, S. K., Hahner, L., Zehr, J., Clegg, D. J., Lagerquist, M. K., \& Ohlsson, C. (2016). Female mice lacking estrogen receptor- $\alpha$ in hypothalamic proopiomelanocortin (POMC) neurons display enhanced estrogenic response on cortical bone mass. Endocrinology, 157(8), 3242-3252. https://doi.org/10.1210/en.2016-1181

32. Furman, D., Chang, J., Lartigue, L., Bolen, C. R., Haddad, F., Gaudilliere, B., Ganio, E. A., Fragiadakis, G. K., Spitzer, M. H., Douchet, I., Daburon, S., Moreau, J., Nolan, G. P., Blanco, P., Déchanet-Merville, J., Dekker, C. L., Jojic, V., Kuo, C. J., Davis, M. M., \& Faustin, B. (2017). Expression of specific inflammasome gene modules stratifies older individuals into two extreme clinical and immunological states. Nature Medicine, 23(2), 174-184. https://doi.org/10.1038/nm.4267 
33. Gangwar, R. S., Vinayachandran, V., Rengasamy, P., Chan, R., Park, B., DiamondZaluski, R., Cara, E. A., Cha, A., Das, L., Asase, C., Maiseyeu, A., Deiuliis, J., Zhong, J., Mitzner, W., Biswal, S., \& Rajagopalan, S. (2020). Differential contribution of bone marrow-derived infiltrating monocytes and resident macrophages to persistent lung inflammation in chronic air pollution exposure. Scientific Reports, 10(1), 1-15. https://doi.org/10.1038/s41598-020-71144-1

34. Garcia-Morales, C., Nandi, S., Zhao, D., Sauter, K. A., Vervelde, L., McBride, D., Sang, H. M., Clinton, M., \& Hume, D. A. (2015). Cell-Autonomous Sex Differences in Gene Expression in Chicken Bone Marrow-Derived Macrophages. The Journal of Immunology, 194(5), 2338-2344. https://doi.org/10.4049/jimmunol.1401982

35. Garin, M. C., Burns, C. M., Kaul, S., \& Cappola, A. R. (2013). The Human Experience With Ghrelin Administration. The Journal of Clinical Endocrinology \& Metabolism, 98(5), 1826-1837. https://doi.org/10.1210/jc.2012-4247

36. Gayle, D. A., Desai, M., Casillas, E., Beloosesky, R., \& Ross, M. G. (2006). Genderspecific orexigenic and anorexigenic mechanisms in rats. Life Sciences, 79(16), 1531-1536. https://doi.org/10.1016/j.Ifs.2006.04.015

37. Gong, L., Yu, L., Gong, X., Wang, C., Hu, N., Dai, X., Peng, C., \& Li, Y. (2020). Exploration of anti-inflammatory mechanism of forsythiaside $A$ and forsythiaside $B$ in CuSO4-induced inflammation in zebrafish by metabolomic and proteomic analyses. Journal of Neuroinflammation, 17(1), 1-21. https://doi.org/10.1186/s12974-020-01855-9

38. Gonzalez-Rey, E., Chorny, A., \& Delgado, M. (2006). Therapeutic Action of 
Ghrelin in a Mouse Model of Colitis. Gastroenterology, 130(6), 1707-1720. https://doi.org/10.1053/j.gastro.2006.01.041

39. Granado, M., Priego, T., Martín, A. I., Villanúa, M. Á., \& López-Calderón, A. (2005). Anti-inflammatory effect of the ghrelin agonist growth hormonereleasing peptide-2 (GHRP-2) in arthritic rats. American Journal of Physiology Endocrinology and Metabolism, 288(3 51-3), 486-492. https://doi.org/10.1152/ajpendo.00196.2004

40. Gutierrez, J. A., Solenberg, P. J., Perkins, D. R., Willency, J. A., Knierman, M. D., Jin, Z., Witcher, D. R., Luo, S., Onyia, J. E., \& Hale, J. E. (2008). Ghrelin octanoylation mediated by an orphan lipid transferase. Proceedings of the National Academy of Sciences, 105(17), 6320-6325. https://doi.org/10.1073/pnas.0800708105

41. Hattori, N. (2009). Expression, regulation and biological actions of growth hormone $(\mathrm{GH})$ and ghrelin in the immune system. Growth Hormone and IGF Research, 19(3), 187-197. https://doi.org/10.1016/j.ghir.2008.12.001

42. Hattori, N., Saito, T., Yagyu, T., Jiang, B.-H., Kitagawa, K., \& Inagaki, C. (2001). GH, GH Receptor, GH Secretagogue Receptor, and Ghrelin Expression in Human T Cells, B Cells, and Neutrophils. The Journal of Clinical Endocrinology \& Metabolism, 86(9), 4284-4291. https://doi.org/10.1210/jcem.86.9.7866

43. Hill-Burns, E. M., \& Clark, A. G. (2009). X-Linked Variation in Immune Response in Drosophila melanogaster. Genetics, 183(4), 1477-1491. https://doi.org/10.1534/genetics.108.093971 
44. Hortová-Kohoutková, M., Lázničková, P., \& Frič, J. (2021). How immune-cell fate and function are determined by metabolic pathway choice: The bioenergetics underlying the immune response. BioEssays, 43(2), 1-15. https://doi.org/10.1002/bies.202000067

45. Howell, O. W., Reeves, C. A., Nicholas, R., Carassiti, D., Radotra, B., Gentleman, S. M., Serafini, B., Aloisi, F., Roncaroli, F., Magliozzi, R., \& Reynolds, R. (2011). Meningeal inflammation is widespread and linked to cortical pathology in multiple sclerosis. Brain, 134(9), 2755-2771. https://doi.org/10.1093/brain/awr182

46. Ibrahim, A., Morais, S., Ferro, A., Lunet, N., \& Peleteiro, B. (2017). Sex-differences in the prevalence of Helicobacter pylori infection in pediatric and adult populations: Systematic review and meta-analysis of 244 studies. Digestive and Liver Disease, 49(7), 742-749. https://doi.org/10.1016/j.dld.2017.03.019

47. likuni, N., Kwan Lam, Q., Lu, L., Matarese, G., \& Cava, A. (2008). Leptin and Inflammation. Current Immunology Reviews, 4(2), 70-79.

https://doi.org/10.2174/157339508784325046

48. Invernizzi, P., Pasini, S., Selmi, C., Gershwin, M. E., \& Podda, M. (2009). Female predominance and $\mathrm{X}$ chromosome defects in autoimmune diseases. Journal of Autoimmunity, 33(1), 12-16. https://doi.org/10.1016/j.jaut.2009.03.005

49. Ip, W. K. E., Hoshi, N., Shouval, D. S., Snapper, S., \& Medzhitov, R. (2017). Antiinflammatory effect of IL-10 mediated by metabolic reprogramming of macrophages. Science, 356(6337), 513-519. 
https://doi.org/10.1126/science.aal3535

50. Jansen, R., Batista, S., Brooks, A. I., Tischfield, J. A., Willemsen, G., Van Grootheest, G., Hottenga, J. J., Milaneschi, Y., Mbarek, H., Madar, V., Peyrot, W., Vink, J. M., Verweij, C. L., de Geus, E. J. C., Smit, J. H., Wright, F. A., Sullivan, P. F., Boomsma, D. I., \& Penninx, B. W. J. H. (2014). Sex differences in the human peripheral blood transcriptome. BMC Genomics, 15(1). https://doi.org/10.1186/1471-2164-15-33

51. Kelley, N., Jeltema, D., Duan, Y., \& He, Y. (2019). The NLRP3 Inflammasome: An Overview of Mechanisms of Activation and Regulation. International Journal of Molecular Sciences, 20(13), 3328. https://doi.org/10.3390/ijms20133328

52. Kevorkov, N. N., Kniazev, I. A., \& Gusev, E. I. (n.d.). [Immunomodulating effects of glucagon]. Problemy Endokrinologii, 33(5), 68-71. http://www.ncbi.nlm.nih.gov/pubmed/3321035

53. Kinjyo, I., Hanada, T., Inagaki-Ohara, K., Mori, H., Aki, D., Ohishi, M., Yoshida, H., Kubo, M., \& Yoshimura, A. (2002). SOCS1/JAB Is a Negative Regulator of LPSInduced Macrophage Activation. Immunity, 17(5), 583-591. https://doi.org/10.1016/S1074-7613(02)00446-6

54. Kinne, R. W., Stuhlmüller, B., \& Burmester, G.-R. (2007). Cells of the synovium in rheumatoid arthritis. Macrophages. Arthritis Research \& Therapy, 9(6), 224. https://doi.org/10.1186/ar2333

55. Klein, S. L., \& Flanagan, K. L. (2016). Sex differences in immune responses. Nature Reviews Immunology, 16(10), 626-638. https://doi.org/10.1038/nri.2016.90 
56. Klein, S. L., Jedlicka, A., \& Pekosz, A. (2010). The Xs and Y of immune responses to viral vaccines. The Lancet Infectious Diseases, 10(5), 338-349. https://doi.org/10.1016/S1473-3099(10)70049-9

57. Kodama, T., Ashitani, J. I., Matsumoto, N., Kangawa, K., \& Nakazato, M. (2008). Ghrelin treatment suppresses neutrophil-dominant inflammation in airways of patients with chronic respiratory infection. Pulmonary Pharmacology and Therapeutics, 21(5), 774-779. https://doi.org/10.1016/j.pupt.2008.05.001

58. Kojima, M., Hosoda, H., Date, Y., Nakazato, M., Matsuo, H., \& Kangawa, K. (1999). Ghrelin is a growth-hormone-releasing acylated peptide from stomach. Nature, 402(6762), 656-660. https://doi.org/10.1038/45230

59. Kovács, T., Szabó-Meleg, E., \& Ábrahám, I. M. (2020). Estradiol-Induced Epigenetically Mediated Mechanisms and Regulation of Gene Expression. International Journal of Molecular Sciences, 21(9), 3177. https://doi.org/10.3390/ijms21093177

60. Kratz, M., Coats, B. R., Hisert, K. B., Hagman, D., Mutskov, V., Peris, E., Schoenfelt, K. Q., Kuzma, J. N., Larson, I., Billing, P. S., Landerholm, R. W., Crouthamel, M., Gozal, D., Hwang, S., Singh, P. K., \& Becker, L. (2014). Metabolic Dysfunction Drives a Mechanistically Distinct Proinflammatory Phenotype in Adipose Tissue Macrophages. Cell Metabolism, 20(4), 614-625. https://doi.org/10.1016/j.cmet.2014.08.010

61. Leme, J. G., Morato, M., \& Souza, M. Z. A. (1975). Anti-inflammatory action of glucagon in rats. British Journal of Pharmacology, 55(1), 65-68. 
https://doi.org/10.1111/j.1476-5381.1975.tb07611.x

62. Li, B., Zeng, M., He, W., Huang, X., Luo, L., Zhang, H., \& Deng, D. Y. B. (2015). Ghrelin protects alveolar macrophages against lipopolysaccharide-induced apoptosis through growth hormone secretagogue receptor 1a-dependent c-jun n-terminal kinase and wnt/ß-catenin signaling and suppresses lung inflammation. Endocrinology, 156(1), 203-217. https://doi.org/10.1210/en.2014-1539

63. Li, C., Chen, Y. H., \& Zhang, K. (2020). Neuroprotective Properties and Therapeutic Potential of Bone Marrow-Derived Microglia in Alzheimer's Disease. American Journal of Alzheimer's Disease and Other Dementias, 35, 1-7. https://doi.org/10.1177/1533317520927169

64. Li, K., Xu, W., Guo, Q., Jiang, Z., Wang, P., Yue, Y., \& Xiong, S. (2009). Differential Macrophage Polarization in Male and Female BALB/c Mice Infected With Coxsackievirus B3 Defines Susceptibility to Viral Myocarditis. Circulation Research, 105(4), 353-364. https://doi.org/10.1161/CIRCRESAHA.109.195230 65. Li, W. G., Gavrila, D., Liu, X., Wang, L., Gunnlaugsson, S., Stoll, L. L., McCormick, M. L., Sigmund, C. D., Tang, C., \& Weintraub, N. L. (2004). Ghrelin Inhibits Proinflammatory Responses and Nuclear Factor-kB Activation in Human Endothelial Cells. Circulation, 109(18), 2221-2226. https://doi.org/10.1161/01.CIR.0000127956.43874.F2

66. Libert, C., Dejager, L., \& Pinheiro, I. (2010). The X chromosome in immune functions: when a chromosome makes the difference. Nature Reviews 
Immunology, 10(8), 594-604. https://doi.org/10.1038/nri2815

67. Lin, S., \& Mei, X. (2021). Role of NLRP3 Inflammasomes in Neuroinflammation Diseases. European Neurology, 83(6), 576-580. https://doi.org/10.1159/000509798

68. Liu, F., Li, Z., He, X., Yu, H., \& Feng, J. (2019). Ghrelin attenuates neuroinflammation and demyelination in experimental autoimmune encephalomyelitis involving NLRP3 inflammasome signaling pathway and pyroptosis. Frontiers in Pharmacology, 10(November), 1-12. https://doi.org/10.3389/fphar.2019.01320

69. Liu, X., Wang, N., Zhu, Y., Yang, Y., Chen, X., Fan, S., Chen, Q., Zhou, H., \& Zheng, J. (2016). Inhibition of Extracellular Calcium Influx Results in Enhanced IL-12 Production in LPS-Treated Murine Macrophages by Downregulation of the CaMKKß-AMPK-SIRT1 Signaling Pathway. Mediators of Inflammation, 2016, 115. https://doi.org/10.1155/2016/6152713

70. Loscalzo, D. E. H. R. C. J. (2008). Cognitive Function Over Time in the Alzheimer's Disease Anti-inflammatory Prevention Trial (ADAPT). Archives of Neurology, 65(7), 896. https://doi.org/10.1001/archneur.2008.65.7.nct70006

71. Mahad, D. H., Trapp, B. D., \& Lassmann, H. (2015). Pathological mechanisms in progressive multiple sclerosis. The Lancet Neurology, 14(2), 183-193. https://doi.org/10.1016/S1474-4422(14)70256-X

72. Makovey, J., Naganathan, V., Seibel, M., \& Sambrook, P. (2007). Gender differences in plasma ghrelin and its relations to body composition and bone an 
opposite-sex twin study. Clinical Endocrinology, 070210034307003-???

https://doi.org/10.1111/j.1365-2265.2007.02768.x

73. Marriott, I., Bost, K. L., \& Huet-Hudson, Y. M. (2006). Sexual dimorphism in expression of receptors for bacterial lipopolysaccharides in murine macrophages: A possible mechanism for gender-based differences in endotoxic shock susceptibility. Journal of Reproductive Immunology, 71(1), 12-27. https://doi.org/10.1016/j.jri.2006.01.004

74. Maruna, P., Gürlich, R., Frasko, R., \& Rosicka, M. (2005). Ghrelin and Leptin Elevation in Postoperative Intra-Abdominal Sepsis. European Surgical Research, 37(6), 354-359. https://doi.org/10.1159/000090336

75. Mathur, N., Mehdi, S. F., Anipindi, M., Aziz, M., Khan, S. A., Kondakindi, H., Lowell, B., Wang, P., \& Roth, J. (2021). Ghrelin as an Anti-Sepsis Peptide: Review. Frontiers in Immunology, 11. https://doi.org/10.3389/fimmu.2020.610363

76. Melgert, B. N., Oriss, T. B., Qi, Z., Dixon-McCarthy, B., Geerlings, M., Hylkema, M. N., \& Ray, A. (2010). Macrophages: Regulators of sex differences in asthma? American Journal of Respiratory Cell and Molecular Biology, 42(5), 595-603. https://doi.org/10.1165/rcmb.2009-00160C

77. Mills, E. L., Kelly, B., Logan, A., Costa, A. S. H., Varma, M., Bryant, C. E., Tourlomousis, P., Däbritz, J. H. M., Gottlieb, E., Latorre, I., Corr, S. C., McManus, G., Ryan, D., Jacobs, H. T., Szibor, M., Xavier, R. J., Braun, T., Frezza, C., Murphy, M. P., \& O'Neill, L. A. (2016). Repurposing mitochondria from ATP production to ROS generation drives a pro-inflammatory phenotype in macrophages that 
depends on succinate oxidation by complex II. Cell, 167(2), 457-470.e13.

https://doi.org/10.1016/j.cell.2016.08.064.Repurposing

78. Milner, M. T., Maddugoda, M., Götz, J., Burgener, S. S., \& Schroder, K. (2021).

The NLRP3 inflammasome triggers sterile neuroinflammation and Alzheimer's disease. Current Opinion in Immunology, 68, 116-124.

https://doi.org/10.1016/j.coi.2020.10.011

79. Mondal, S., \& Rai, U. (1999). Sexual Dimorphism in Phagocytic Activity of Wall Lizard's Splenic Macrophages and Its Control by Sex Steroids. General and Comparative Endocrinology, 116(2), 291-298.

https://doi.org/10.1006/gcen.1999.7370

80. Mosha, F. (2020). Gender Differences in Human Immunodeficiency Virus (HIV) Disease Progression and Treatment Outcomes. In AIDS Updates - Recent Advances and New Perspectives [Working Title]. IntechOpen. https://doi.org/10.5772/intechopen.92898

81. Müller, T. D., Nogueiras, R., Andermann, M. L., Andrews, Z. B., Anker, S. D., Argente, J., Batterham, R. L., Benoit, S. C., Bowers, C. Y., Broglio, F., Casanueva, F. F., D’Alessio, D., Depoortere, I., Geliebter, A., Ghigo, E., Cole, P. A., Cowley, M., Cummings, D. E., Dagher, A., ... Tschöp, M. H. (2015). Ghrelin. Molecular Metabolism, 4(6), 437-460. https://doi.org/10.1016/j.molmet.2015.03.005

82. Nakada, D., Oguro, H., Levi, B. P., Ryan, N., Kitano, A., Saitoh, Y., Takeichi, M., Wendt, G. R., \& Morrison, S. J. (2014). Oestrogen increases haematopoietic stem-cell self-renewal in females and during pregnancy. Nature, 505(7484), 555- 
558. https://doi.org/10.1038/nature12932

83. Netea, M. G., Balkwill, F., Chonchol, M., Cominelli, F., Donath, M. Y., GiamarellosBourboulis, E. J., Golenbock, D., Gresnigt, M. S., Heneka, M. T., Hoffman, H. M., Hotchkiss, R., Joosten, L. A. B., Kastner, D. L., Korte, M., Latz, E., Libby, P., Mandrup-Poulsen, T., Mantovani, A., Mills, K. H. G., ... Dinarello, C. A. (2017). A guiding map for inflammation. Nature Immunology, 18(8), 826-831. https://doi.org/10.1038/ni.3790

84. Nieves, W., Hung, L.-Y., Oniskey, T. K., Boon, L., Foretz, M., Viollet, B., \& Herbert, D. R. (2016). Myeloid-Restricted AMPKa1 Promotes Host Immunity and Protects against IL-12/23p40-Dependent Lung Injury during Hookworm Infection. The Journal of Immunology, 196(11), 4632-4640.

https://doi.org/10.4049/jimmunol.1502218

85. O’Driscoll, D. N., De Santi, C., McKiernan, P. J., McEneaney, V., Molloy, E. J., \& Greene, C. M. (2017). Expression of X-linked Toll-like receptor 4 signaling genes in female vs. male neonates. Pediatric Research, 81(5), 831-837. https://doi.org/10.1038/pr.2017.2

86. Otero, M., Nogueiras, R., Lago, F., Dieguez, C., Gomez-Reino, J. J., \& Gualillo, O. (2004). Chronic inflammation modulates ghrelin levels in humans and rats. Rheumatology, 43(3), 306-310. https://doi.org/10.1093/rheumatology/keh055

87. Pereira, J. A. da S., Silva, F. C. da, \& de Moraes-Vieira, P. M. M. (2017). The Impact of Ghrelin in Metabolic Diseases: An Immune Perspective. Journal of Diabetes Research, 2017, 1-15. https://doi.org/10.1155/2017/4527980 
88. Phiel, K. L., Henderson, R. A., Adelman, S. J., \& Elloso, M. M. (2005). Differential estrogen receptor gene expression in human peripheral blood mononuclear cell populations. Immunology Letters, 97(1), 107-113.

https://doi.org/10.1016/j.imlet.2004.10.007

89. Pirmohamed, M., James, S., Meakin, S., Green, C., Scott, A. K., Walley, T. J., Farrar, K., Park, B. K., \& Breckenridge, A. M. (2004). Adverse drug reactions as cause of admission to hospital: prospective analysis of 18820 patients. BMJ, 329(7456), 15-19. https://doi.org/10.1136/bmj.329.7456.15

90. Qian, B.-Z., Li, J., Zhang, H., Kitamura, T., Zhang, J., Campion, L. R., Kaiser, E. A., Snyder, L. A., \& Pollard, J. W. (2011). CCL2 recruits inflammatory monocytes to facilitate breast-tumour metastasis. Nature, 475(7355), 222-225. https://doi.org/10.1038/nature10138

91. Radtke, F. A., Chapman, G., Hall, J., \& Syed, Y. A. (2017). Modulating neuroinflammation to treat neuropsychiatric disorders. BioMed Research International, 2017. https://doi.org/10.1155/2017/5071786

92. Ramond, E., Jamet, A., Coureuil, M., \& Charbit, A. (2019). Pivotal Role of Mitochondria in Macrophage Response to Bacterial Pathogens. Frontiers in Immunology, 10. https://doi.org/10.3389/fimmu.2019.02461

93. Rashid, M., \& Coombs, K. M. (2019). Serum-reduced media impacts on cell viability and protein expression in human lung epithelial cells. Journal of Cellular Physiology, 234(6), 7718-7724. https://doi.org/10.1002/jcp.27890

94. Rettew, J. A., Huet-Hudson, Y. M., \& Marriott, I. (2008). Testosterone reduces 
macrophage expression in the mouse of toll-like receptor 4 , a trigger for inflammation and innate immunity. Biology of Reproduction, 78(3), 432-437. https://doi.org/10.1095/biolreprod.107.063545

95. Rettew, J. A., Huet, Y. M., \& Marriott, I. (2009). Estrogens augment cell surface TLR4 expression on murine macrophages and regulate sepsis susceptibility in vivo. Endocrinology, 150(8), 3877-3884. https://doi.org/10.1210/en.2009-0098

96. Rhea, E. M., Salameh, T. S., Gray, S., Niu, J., Banks, W. A., \& Tong, J. (2018). Ghrelin transport across the blood-brain barrier can occur independently of the growth hormone secretagogue receptor. Molecular Metabolism, 18(September), 88-96. https://doi.org/10.1016/j.molmet.2018.09.007

97. Ribas, V., Drew, B. G., Le, J. A., Soleymani, T., Daraei, P., Sitz, D., Mohammad, L., Henstridge, D. C., Febbraio, M. A., Hewitt, S. C., Korach, K. S., Bensinger, S. J., \& Hevener, A. L. (2011). Myeloid-specific estrogen receptor deficiency impairs metabolic homeostasis and accelerates atherosclerotic lesion development. Proceedings of the National Academy of Sciences, 108(39), 16457-16462. https://doi.org/10.1073/pnas.1104533108

98. Roth, G. A., Abate, D., Abate, K. H., Abay, S. M., Abbafati, C., Abbasi, N., Abbastabar, H., Abd-Allah, F., Abdela, J., Abdelalim, A., Abdollahpour, I., Abdulkader, R. S., Abebe, H. T., Abebe, M., Abebe, Z., Abejie, A. N., Abera, S. F., Abil, O. Z., Abraha, H. N., ... Murray, C. J. L. (2018). Global, regional, and national age-sex-specific mortality for 282 causes of death in 195 countries and territories, 1980-2017: a systematic analysis for the Global Burden of Disease 
Study 2017. The Lancet, 392(10159), 1736-1788. https://doi.org/10.1016/S0140$6736(18) 32203-7$

99. Rubin, J. B., Lagas, J. S., Broestl, L., Sponagel, J., Rockwell, N., Rhee, G., Rosen, S. F., Chen, S., Klein, R. S., Imoukhuede, P., \& Luo, J. (2020). Sex differences in cancer mechanisms. Biology of Sex Differences, 11(1), 1-29.

https://doi.org/10.1186/s13293-020-00291-x

100. Russell, J. A., \& Walley, K. R. (2010). Vasopressin and Its Immune Effects in Septic Shock. Journal of Innate Immunity, 2(5), 446-460.

https://doi.org/10.1159/000318531

101. Sag, D., Carling, D., Stout, R. D., \& Suttles, J. (2008). Adenosine 5'Monophosphate-Activated Protein Kinase Promotes Macrophage Polarization to an Anti-Inflammatory Functional Phenotype. The Journal of Immunology, 181(12), 8633-8641. https://doi.org/10.4049/jimmunol.181.12.8633

102. Salminen, A., Hyttinen, J. M. T., \& Kaarniranta, K. (2011). AMP-activated protein kinase inhibits NF-KB signaling and inflammation: impact on healthspan and lifespan. Journal of Molecular Medicine, 89(7), 667-676.

https://doi.org/10.1007/s00109-011-0748-0

103. Santos, V. V., Stark, R., Rial, D., Silva, H. B., Bayliss, J. A., Lemus, M. B., Davies, J. S., Cunha, R. A., Prediger, R. D., \& Andrews, Z. B. (2017). Acyl ghrelin improves cognition, synaptic plasticity deficits and neuroinflammation following amyloid $\beta$ (Aß1-40) administration in mice. Journal of Neuroendocrinology, 29(5). https://doi.org/10.1111/jne.12476 
104. Sas, L., Lardon, F., Vermeulen, P. B., Hauspy, J., Van Dam, P., Pauwels, P., Dirix, L. Y., \& Van Laere, S. J. (2012). The interaction between ER and NFKB in resistance to endocrine therapy. Breast Cancer Research, 14(4), 212. https://doi.org/10.1186/bcr3196

105. Satou, M., Nakamura, Y., Ando, H., \& Sugimoto, H. (2011). Understanding the functional significance of ghrelin processing and degradation. Peptides, 32(11), 2183-2190. https://doi.org/10.1016/j.peptides.2011.06.029

106. Savarin, C., Dutta, R., \& Bergmann, C. C. (2018). Distinct gene profiles of bone marrow-derived macrophages and microglia during neurotropic coronavirus-induced demyelination. Frontiers in Immunology, 9(JUN). https://doi.org/10.3389/fimmu.2018.01325

107. Sawalha, A. H., Harley, J. B., \& Scofield, R. H. (2009). Autoimmunity and Klinefelter's syndrome: When men have two X chromosomes. Journal of Autoimmunity, 33(1), 31-34. https://doi.org/10.1016/j.jaut.2009.03.006

108. Scotland, R. S., Stables, M. J., Madalli, S., Watson, P., \& Gilroy, D. W. (2011). Sex differences in resident immune cell phenotype underlie more efficient acute inflammatory responses in female mice. Blood, 118(22), 59185927. https://doi.org/10.1182/blood-2011-03-340281

109. Serra-Prat, M., Papiol, M., Monteis, R., Palomera, E., \& Cabré, M. (2015). Relationship between plasma ghrelin levels and sarcopenia in elderly subjects: A cross-sectional study. The Journal of Nutrition, Health \& Aging, 19(6), 669-672. https://doi.org/10.1007/s12603-015-0550-8 
110. Shi, J., Fan, J., Su, Q., \& Yang, Z. (2019). Cytokines and Abnormal Glucose and Lipid Metabolism. Frontiers in Endocrinology, 10.

https://doi.org/10.3389/fendo.2019.00703

111. Shimizu, Y., Nagaya, N., Isobe, T., Imazu, M., Okumura, H., Hosoda, H., Kojima, M., Kangawa, K., \& Kohno, N. (2003). Increased plasma ghrelin level in lung cancer cachexia. Clinical Cancer Research, 9(2), 774-778.

112. Slavich, G. M. (2015). Understanding inflammation, its regulation, and relevance for health: A top scientific and public priority. Brain, Behavior, and Immunity, 45, 13-14. https://doi.org/10.1016/j.bbi.2014.10.012

113. Song, N., Liu, Z. S., Xue, W., Bai, Z. F., Wang, Q. Y., Dai, J., Liu, X., Huang, Y. J., Cai, H., Zhan, X. Y., Han, Q. Y., Wang, H., Chen, Y., Li, H. Y., Li, A. L., Zhang, X. M., Zhou, T., \& Li, T. (2017). NLRP3 Phosphorylation Is an Essential Priming Event for Inflammasome Activation. Molecular Cell, 68(1), 185-197.e6. https://doi.org/10.1016/j.molcel.2017.08.017

114. Spolarics, Z. (2007). The X-files of inflammation. Shock, 27(6), 597-604. https://doi.org/10.1097/SHK.0b013e31802e40bd

115. Srivastava, A., Srivastava, P., \& Verma, R. (2019). Role of bone marrowderived macrophages (BMDMs) in neurovascular interactions during stroke. Neurochemistry International, 129(May), 104480. https://doi.org/10.1016/j.neuint.2019.104480

116. Straub, R. H., Cutolo, M., Buttgereit, F., \& Pongratz, G. (2010). Energy regulation and neuroendocrine-immune control in chronic inflammatory 
diseases. Journal of Internal Medicine, 267(6), 543-560.

https://doi.org/10.1111/j.1365-2796.2010.02218.x

117. Sun, Q., Li, J., \& Gao, F. (2014). New insights into insulin: The antiinflammatory effect and its clinical relevance. World Journal of Diabetes, 5(2), 89. https://doi.org/10.4239/wjd.v5.i2.89

118. Sun, Y., Wang, P., Zheng, H., \& Smith, R. G. (2004). Ghrelin stimulation of growth hormone release and appetite is mediated through the growth hormone secretagogue receptor. Proceedings of the National Academy of Sciences, 101(13), 4679-4684. https://doi.org/10.1073/pnas.0305930101

119. Takaku, M., Tomita, S., Kurobe, H., Kihira, Y., Morimoto, A., Higashida, M., Ikeda, Y., Ushiyama, A., Hashimoto, I., Nakanishi, H., \& Tamaki, T. (2012).

Systemic preconditioning by a prolyl hydroxylase inhibitor promotes prevention of skin flap necrosis via HIF-1-induced bone marrow-derived cells. PLOS ONE, 7(8). https://doi.org/10.1371/journal.pone.0042964

120. Tannahill, G. M., Curtis, A. M., Adamik, J., Palsson-McDermott, E. M., McGettrick, A. F., Goel, G., Frezza, C., Bernard, N. J., Kelly, B., Foley, N. H., Zheng, L., Gardet, A., Tong, Z., Jany, S. S., Corr, S. C., Haneklaus, M., Caffrey, B. E., Pierce, K., Walmsley, S., ... O'Neill, L. A. J. (2013). Succinate is an inflammatory signal that induces IL-1 $\beta$ through HIF-1 $\alpha$. Nature, 496(7444), 238-242.

https://doi.org/10.1038/nature11986

121. Terawaki, K., Kashiwase, Y., Sawada, Y., Hashimoto, H., Yoshimura, M., Ohbuchi, K., Sudo, Y., Suzuki, M., Miyano, K., Shiraishi, S., Higami, Y., Yanagihara, 
K., Hattori, T., Kase, Y., Ueta, Y., \& Uezono, Y. (2017). Development of ghrelin resistance in a cancer cachexia rat model using human gastric cancer-derived 85As2 cells and the palliative effects of the Kampo medicine rikkunshito on the model. PLOS ONE, 12(3), e0173113.

https://doi.org/10.1371/journal.pone.0173113

122. Vila, G., Maier, C., Riedl, M., Nowotny, P., Ludvik, B., Luger, A., \& Clodi, M. (2007). Bacterial endotoxin induces biphasic changes in plasma ghrelin in healthy humans. Journal of Clinical Endocrinology and Metabolism, 92(10), 3930-3934. https://doi.org/10.1210/jc.2007-1194

123. Walker, K. A., Ficek, B. N., \& Westbrook, R. (2019). Understanding the Role of Systemic Inflammation in Alzheimer's Disease. ACS Chemical Neuroscience, 10(8), 3340-3342.

https://doi.org/10.1021/acschemneuro.9b00333

124. Wang. (2009). The inhibitory effect of ghrelin on sepsis-induced inflammation is mediated by the MAPK phosphatase-1. International Journal of Molecular Medicine, 25(01). https://doi.org/10.3892/ijmm_00000326

125. Wang, H., \& Ye, J. (2015). Regulation of energy balance by inflammation: Common theme in physiology and pathology. Reviews in Endocrine and Metabolic Disorders, 16(1), 47-54. https://doi.org/10.1007/s11154-014-9306-8

126. Waseem, T., Duxbury, M., Ito, H., Ashley, S. W., \& Robinson, M. K. (2008). Exogenous ghrelin modulates release of pro-inflammatory and antiinflammatory cytokines in LPS-stimulated macrophages through distinct signaling 
pathways. Surgery, 143(3), 334-342. https://doi.org/10.1016/j.surg.2007.09.039

127. Washburn, T. C., Medearis, D. N., \& Childs, B. (1965). Sex differences in susceptibility to infection. Pediatrics, 35, 57-64.

http://www.ncbi.nlm.nih.gov/pubmed/14223226

128. Wegner, A., Benson, S., Rebernik, L., Spreitzer, I., Jäger, M., Schedlowski, M., Elsenbruch, S., \& Engler, H. (2017). Sex differences in the pro-inflammatory cytokine response to endotoxin unfold in vivo but not ex vivo in healthy humans. Innate Immunity, 23(5), 432-439. https://doi.org/10.1177/1753425917707026

129. Weisberg, S. P., McCann, D., Desai, M., Rosenbaum, M., Leibel, R. L., \& Ferrante, A. W. (2003). Obesity is associated with macrophage accumulation in adipose tissue. Journal of Clinical Investigation, 112(12), 1796-1808. https://doi.org/10.1172/JCI200319246

130. Weissbein, U., Plotnik, O., Vershkov, D., \& Benvenisty, N. (2017). Cultureinduced recurrent epigenetic aberrations in human pluripotent stem cells. PLOS Genetics, 13(8), e1006979. https://doi.org/10.1371/journal.pgen.1006979

131. Wren, A. M., Small, C. J., Ward, H. L., Murphy, K. G., Dakin, C. L., Taheri, S., Kennedy, A. R., Roberts, G. H., Morgan, D. G. A., Ghatei, M. A., \& Bloom, S. R. (2000). The Novel Hypothalamic Peptide Ghrelin Stimulates Food Intake and Growth Hormone Secretion. Endocrinology, 141(11), 4325-4328. https://doi.org/10.1210/endo.141.11.7873

132. Xiao, L., Zheng, H., Li, J., Wang, Q., \& Sun, H. (2020). Neuroinflammation Mediated by NLRP3 Inflammasome After Intracerebral Hemorrhage and 
Potential Therapeutic Targets. Molecular Neurobiology, 57(12), 5130-5149.

https://doi.org/10.1007/s12035-020-02082-2

133. Yamada, C. (2021). Relationship between orexigenic peptide ghrelin signal, gender difference and disease. International Journal of Molecular Sciences, 22(7). https://doi.org/10.3390/ijms22073763

134. Yamada, C., lizuka, S., Nahata, M., Hattori, T., \& Takeda, H. (2020).

Vulnerability to psychological stress-induced anorexia in female mice depends on blockade of ghrelin signal in nucleus tractus solitarius. British Journal of Pharmacology, 177(20), 4666-4682. https://doi.org/10.1111/bph.15219

135. Yasrebi, A., Hsieh, A., Mamounis, K. J., Krumm, E. A., Yang, J. A., Magby, J., Hu, P., \& Roepke, T. A. (2016). Differential gene regulation of GHSR signaling pathway in the arcuate nucleus and NPY neurons by fasting, diet-induced obesity, and 17ß-estradiol. Molecular and Cellular Endocrinology, 422, 42-56. https://doi.org/10.1016/j.mce.2015.11.007

136. Yin, Y., Li, Y., \& Zhang, W. (2014). The Growth Hormone Secretagogue Receptor: Its Intracellular Signaling and Regulation. International Journal of Molecular Sciences, 15(3), 4837-4855. https://doi.org/10.3390/ijms15034837

137. Ziko, I., Sominsky, L., De Luca, S. N., Lelngei, F., \& Spencer, S. J. (2018). Acylated ghrelin suppresses the cytokine response to lipopolysaccharide and does so independently of the hypothalamic-pituitary-adrenal axis. Brain, Behavior, and Immunity, 74, 86-95. https://doi.org/10.1016/j.bbi.2018.07.011 